\title{
Long-term ice sheet-climate interactions under anthropogenic greenhouse forcing simulated with a complex Earth System Model
}

\author{
Miren Vizcaíno · Uwe Mikolajewicz • \\ Matthias Gröger · Ernst Maier-Reimer • \\ Guy Schurgers · Arne M. E. Winguth
}

Received: 16 April 2007/ Accepted: 9 January 2008/Published online: 30 January 2008

(C) Springer-Verlag 2008

\begin{abstract}
Several multi-century and multi-millennia simulations have been performed with a complex Earth System Model (ESM) for different anthropogenic climate change scenarios in order to study the long-term evolution of sea level and the impact of ice sheet changes on the climate system. The core of the ESM is a coupled coarseresolution Atmosphere-Ocean General Circulation Model (AOGCM). Ocean biogeochemistry, land vegetation and ice sheets are included as components of the ESM. The Greenland Ice Sheet (GrIS) decays in all simulations, while the Antarctic ice sheet contributes negatively to sea level rise, due to enhanced storage of water caused by larger snowfall rates. Freshwater flux increases from Greenland are one order of magnitude smaller than total freshwater flux increases into the North Atlantic basin (the sum of the
\end{abstract}

\footnotetext{
M. Vizcaíno · U. Mikolajewicz · M. Gröger ·

E. Maier-Reimer · G. Schurgers

Max-Planck-Institut für Meteorologie,

Bundestrasse 53, 20146 Hamburg, Germany
}

M. Vizcaíno $(\varangle)$

Department of Geography,

University of California, Berkeley, CA, USA

e-mail: mirenvt@atmos.berkeley.edu

Present Address:

M. Gröger

IFM-GEOMAR, Kiel, Germany

Present Address:

G. Schurgers

Department of Physical Geography and Ecosystems Analysis, Lund University, Lund, Sweden

A. M. E. Winguth

Department of Atmospheric and Oceanic Sciences,

Center for Climatic Research, Madison, USA contribution from changes in precipitation, evaporation, run-off and Greenland meltwater) and do not play an important role in changes in the strength of the North Atlantic Meridional Overturning Circulation (NAMOC). The regional climate change associated with weakening/ collapse of the NAMOC drastically reduces the decay rate of the GrIS. The dynamical changes due to GrIS topography modification driven by mass balance changes act first as a negative feedback for the decay of the ice sheet, but accelerate the decay at a later stage. The increase of surface temperature due to reduced topographic heights causes a strong acceleration of the decay of the ice sheet in the long term. Other feedbacks between ice sheet and atmosphere are not important for the mass balance of the GrIS until it is reduced to $3 / 4$ of the original size. From then, the reduction in the albedo of Greenland strongly accelerates the decay of the ice sheet.

Keywords Ice sheets - Anthropogenic climate change Meridional overturning circulation .

Earth system modelling $\cdot$ Sea level

\section{Introduction}

The melting of glaciers and the thermal expansion of the oceans associated with anthropogenic climate change are expected to produce substantial sea level changes during the next few centuries (Meehl et al. 2007). The continentalsize glaciers on Earth, the Greenland and Antarctic ice sheets (GrIS and AIS), store a volume of water equivalent to a sea level rise of 7.2 and $61.1 \mathrm{~m}$, respectively (Church et al. 2001). While half of the current ablation in the GrIS is due to surface melting, almost all ablation happens as calving at the margin of the AIS, due to the very low 
atmospheric temperatures. Alley et al. (2005) and Gregory et al. (2004) showed that for a uniform warming of more than $3 \mathrm{~K}$, the GrIS would begin to decay, disappearing in between 1000 and several thousand years, depending on the magnitude of the warming.

In addition to producing changes in sea level, future modifications of the ice sheets could produce changes in the climate system via changes in ocean circulation, surface albedo, and/or atmospheric circulation patterns. Such modifications of climate could potentially affect the mass balance of the ice sheets and therefore play an important role in their own evolution. There are a few examples of modelling studies in the literature performed with coupled ice sheet-climate models with the aim of identifying and quantifying these feedbacks between ice sheets and climate for both the cases of past and future climate. For the studies of past climates, Intermediate Complexity Models (EMICs, for an overview see Petoukhov et al. 2005) have been used as tool, due to the long time scales and the limitations imposed by computational resources. For future climate projections, some studies have focused exclusively on the feedbacks between ice sheets and ocean (Huybrechts et al. 2002; Fichefet et al. 2003), while others have investigated the feedbacks between ice sheets and atmosphere as well (Ridley et al. 2005; Driesschaert et al. 2007). Only the studies of Ridley et al. (2005), with HadCM3, and Mikolajewicz et al. (2007b) were performed with General Circulation Models (GCMs) both for the ocean and atmosphere, and with full coupling between the three components ice sheet, ocean, and atmosphere. This type of tool enables the investigation of the feedbacks between ice sheets and both the circulations of atmosphere and ocean. Feedback studies using models of intermediate complexity may allow the estimate of some of the relevant feedbacks but are in general limited by the strong simplifications of atmospheric physics and dynamics and their potential impact on some of the simulated feedbacks.

The albedo-feedback is considered to have played a key role in the growth of ice sheets during past glacial inceptions (Kageyama et al. 2004; Calov et al. 2005). Manabe and Broccoli (1985) found that the albedo and topographic effects of ice sheets alone explain much of the northern hemisphere cooling identified in paleoclimatic records of the last glacial maximum. In Ridley et al. (2005), albedo changes act as a negative feedback for the decay of the GrIS under a constant $4 \times \mathrm{CO}_{2}$ scenario. The evolution of convective cells, with rising warm air over the areas becoming ice-free and descending air over the ice sheet, originates the transport of cold air from the interior of the ice sheet into the ablation zones at the margins of the ice sheet, reducing surface melting.

The height-feedback, i.e., the modification of surface temperature due to changes in elevation, can play an important role in the processes of growth and decay of ice sheets, for instance at glacial inception (Gallee et al. 1992; Wang and Mysak 2002), or in the future development of the GrIS. In Huybrechts and de Wolde (1999) a substantial contribution of this feedback to the decay rate of the GrIS is shown. These authors also investigated the effect on the velocity field of changes in topography driven by changes in the surface mass balance. They found a deceleration of the decay rate during a first phase, which turned into acceleration at a later stage.

The freshening of ocean waters at deep convection sites by meltwater from the ice sheets could potentially modify the strength of the NAMOC. Several authors have investigated this issue for past climates and future climate projections. The discharge of meltwater from the northern hemisphere ice sheets has been proposed as the triggering mechanism for abrupt climate change in the past at the time of the Younger Dryas (Broecker et al. 1988; Maier-Reimer and Mikolajewicz 1989). Fichefet et al. (2003) found a substantial weakening of the NAMOC in response to increased meltwater fluxes from the GrIS in a twenty-first century simulation. Driesschaert et al. (2007) investigated the response of the climate system to different greenhouse gas scenarios with a three-dimensional (3D) EMIC including a dynamic ice sheet component. They found a noticeable weakening of the NAMOC due to freshwater fluxes from the GrIS only under the forcing of the most extreme scenario.

A reduction in northward ocean heat transport due to a collapsed or weakened NAMOC potentially modifies the climate of the North Atlantic region (e.g. Stouffer et al. 2006, Fig. 4). This regional climate change could produce a reduction of meltwater fluxes from the ice sheets in the region, acting as a mechanism stabilising the NAMOC. This negative feedback between ice sheet melting and NAMOC changes could modify the time scales of recovery of the NAMOC after strong meltwater fluxes pulses both in past and future climates. This mechanism has not been received much attention in the literature yet. In the greenhouse gas simulation of Swingedouw et al. (2006), with a coupled-ocean atmosphere model and a simple landice melting parameterisation, the freshwater forcing from ice sheet melting increases nearly linearly from 0 to $0.2 \mathrm{~Sv}$ in 140 years of $1 \%$ per year increase of atmospheric $\mathrm{CO}_{2}$. The NAMOC weakens from 10 to $5 \mathrm{~Sv}$, with a substantial contribution of ice sheet melting to this weakening. The negative atmospheric temperature anomaly associated with this decline has its maximum far from Greenland, over the Barents Sea, being its absolute value less than $2 \mathrm{~K}$ over Greenland. The mechanism suggested above does not seem relevant in this study, since ice sheet melting does not appear to decrease substantially following the weakening of the NAMOC. Similarly, in the $2 \times \mathrm{CO}_{2}$ simulation of 
Swingedouw et al. (2007), the impact on the Greenland climate of the reduced ocean heat transport accompanying the decline of the NAMOC does not prevent land-ice melting from causing the shutdown of the NAMOC.

Changes in the topography of the ice sheets can modify the general circulation of the atmosphere. Modelling studies of past climates indicate that the path of the jet stream is highly dependent on the topography of the Laurentide ice sheet (Manabe and Broccoli 1985; Cook and Held 1988). The changes in the atmosphere that the absence of the GrIS would cause in the case of its complete deglaciation have been investigated in studies where the ice sheet is absent either from a pre-industrial basic state (e.g., Lunt et al. 2004; Toniazzo et al. 2004; Junge et al. 2005) or from a human-perturbed climate (Ridley et al. 2005). These studies found a regional impact of the absence of the GrIS, with maximal warming in Greenland due to drastic reduction of surface albedo and topographic height, and substantial changes in the path of the storm track and in the mean circulation of the atmosphere in the northern high latitudes.

A key question in the investigation of these feedbacks between ice sheets and climate is whether there exist thresholds for them to begin to operate, as well as the extent to which the interactions of ice sheets and climate behave in a non-linear way. In Ridley et al. (2005) the feedbacks between the GrIS and climate begin to contribute to the mass budget of the ice sheet from the time when the ice sheet has decayed to $2 / 3$ of its original volume. The response of the ocean circulation to changes in freshwater fluxes can be highly non-linear, especially if the model is close to a bifurcation point of the NAMOC. The changes in ocean heat transport resulting from a collapse of the NAMOC are partially compensated by enhanced atmospheric transport of latent heat (and thus moisture) in the North Atlantic drainage basin (e.g. Nakamura et al. 1994; Schiller et al. 1997). Once the model has crossed the bifurcation point of the NAMOC even a reduction of additional freshwater supply does not necessarily lead to a substantial recovery of the NAMOC (e.g. Stommel 1961; Manabe and Stouffer 1988; Mikolajewicz and Maier-Reimer 1994; Rahmstorf and Willebrand 1995). Whether such a bifurcation point of the NAMOC exists under present conditions is subject of debate. Several studies have investigated whether the GrIS would regrow after its complete deglaciation if pre-industrial or present-day levels of atmospheric $\mathrm{CO}_{2}$ would be reestablished (Crowley and Baum 1995; Calov et al. 2005; Toniazzo et al. 2004; Lunt et al. 2004).

In our study, a global ice sheet model has been bi-directionally coupled to a complex climate model with an Atmosphere-Ocean General Circulation Model (AOGCM) as core in order to study the long-term evolution of global ice sheets under anthropogenic forcing and the impact of changes in their mass balance on the climate system. With this approach, changes due to ice dynamics can be taken into account, as well as the feedbacks between ice sheets and climate and other feedbacks between other main components of the climate system (ocean, atmosphere, global vegetation, and carbon cycle). The relatively coarse resolution of the atmospheric component (T21) represents a compromise between the needs of detailed physical representation of processes and the realisation of long simulations, in order to investigate the long-term response of the climate system to anthropogenic greenhouse forcing and to identify the non-linearities and critical thresholds that could arise.

This paper is a follow-up of Mikolajewicz et al. (2007a) (in the following Mik07), where this new Earth System Model (ESM) is introduced with a general description of its components, validation of the model against observations, and results from multi-millennia ensemble simulations describing the long-term response of the Earth System to prescribed carbon emissions in the twenty-first century. These emissions follow three IPCC scenarios of increasing greenhouse forcing: B1, A1B and A2. The paper aims to extend the results from Mik07 by focusing in the role of ice sheets on climate changes. The main goals of this paper are to present a detailed description of the coupling of the ice sheet component to the rest of components in this ESM, and to identify the feedbacks between ice sheets and climate relevant to anthropogenic climate change. In order to accomplish the second goal, two different sets of simulations are analysed: a set of simulations where the atmospheric carbon dioxide concentration is increased by $1 \%$ per year until stabilisation at two, three and four times pre-industrial levels, and a second set of longer simulations following the $\mathrm{CO}_{2}$ emission scenario A2 until year 2100 and an exponential decrease of emissions afterwards. The results of the first set of simulations are presented first, in order to explore the existence of thresholds and non-linearities in the climate system by means of the analysis of its response to increasing anthropogenic greenhouse forcing. By the end of a longer simulation with forcing corresponding to the high emission scenario A2, the GrIS almost disappears. This simulation and a simulation with the same setup but not including the feedbacks between ice sheets and climate are compared in order to evaluate the importance of these feedbacks for the mass balance of the GrIS, as well as the impact on the climate system of the disappearance of the GrIS.

The structure of this paper is as follows: first the ESM is described in Sect. 2, focusing on the ice sheet model and its coupling to the atmosphere and ocean components. In Sect. 3, the setup of both stabilisation and A2 simulations is presented and the global changes in the ocean and atmosphere in the stabilisation simulations are described. 
In Sect. 4, changes in the mass balance of global ice sheets and in sea level in the stabilisation simulations are shown. Section 5 focuses on the feedbacks between ice sheets and the climate system. The results of the A2 simulations are used here in order to complement the findings from the stabilisation simulations. Summary and discussion are given in Sect. 6.

\section{The model}

\subsection{The Earth System Model}

The core of the ESM is an Atmosphere-Ocean General Circulation Model. The ESM includes the main physical and biogeochemical components of the Earth System via fully coupled models of ocean biogeochemistry (modelled with HAMOCC, Maier-Reimer 1993), land vegetation (modelled with LPJ, Sitch et al. 2003), and ice sheets (modelled with the 3D model SICOPOLIS, Greve 1995). The ocean biogeochemistry and land vegetation components together with a well-mixed atmospheric box constitute a closed carbon cycle. Therefore, atmospheric carbon dioxide concentrations can be calculated prognostically by the model when carbon emissions are prescribed. The only external forcing used in the simulations presented here with this ESM are carbon emissions or prescribed atmospheric carbon dioxide concentrations.

Long (multi-millennia) simulations can be performed with this model due to its coarse resolution (T21 for the atmosphere model). In order to save further computation time and to facilitate the long-term simulations, a periodically synchronous coupling technique has been applied (Voss and Sausen 1996). The underlying assumption is that the long-term memory resides in ocean and ice sheets and - to a lesser extent-in the land-biosphere, while the atmosphere model consumes by far the most computation time. Assuming that the atmosphere is on time-scales of decades and longer in a statistical equilibrium with the underlying fields of ice sheets, sea surface temperature and sea ice, allows to integrate the coupled model with alternating periods of fully coupled mode and periods where the slower components are driven in stand-alone mode with forcing derived from previous fully coupled periods. For the ocean the heat fluxes are modified using a nonlinear anomaly energy balance model. A detailed description of this technique is given in Mik07. The model with prescribed ice sheets has been applied to several studies of the Eemian and Holocene (Schurgers et al. 2006, 2007; Gröger et al. 2007). The full model with interactive ice sheets has been used for several studies of anthropogenic climate change (Mikolajewicz et al. 2007a; Winguth et al. 2005; Schurgers et al. 2008).
The atmosphere is modelled with ECHAM3 (Roeckner et al. 1992) at a horizontal resolution of T21 (approximately $5.6^{\circ}$ ) and a vertical resolution of 19 layers. The prognostic variables are vorticity, divergence, temperature, humidity, surface pressure and cloud water. The time step is $40 \mathrm{~min}$.

The ocean model LSG2 is an improved version of LSG by Maier-Reimer et al. (1993), with a horizontal resolution of $5.6^{\circ}$ in two overlapping grids $(64 \times 64$ points on an Arakawa $\mathrm{E}$ grid). Main modifications from the original LSG are the inclusion of a parameterisation accounting for the sub-grid-scale tracer transport due to eddies (Gent et al. 1995) and the use of a second-order total variation diminishing scheme for tracer advection (Sweby 1984). The vertical resolution is 22 vertical layers, with thickness varying with depth from $50 \mathrm{~m}$ in the uppermost layer to almost $800 \mathrm{~m}$ at 5,600 $\mathrm{m}$ depth. The time step of the model is 5 days, but a time step of 1 day is used for the thermodynamics of the surface layer. A simple dynamic sea ice model is included. The coupling time step between atmosphere and ocean is 1 day.

The model's simulated climate has a cold bias in comparison to observations in high latitudes and a warm bias in low latitudes. Especially in northern hemisphere winter, the model's climate is $10 \mathrm{~K}$ colder over the Arctic. This bias is related to the underestimation of wintertime clouds over the Arctic. In the southern hemisphere, the temperature errors are smaller and the simulated zonal mean surface air temperatures lie within the range spanned by different climatologies. In summer, the simulated precipitation over the Arctic is about twice as strong as in the observational estimates. Near the South Pole, the model overestimates precipitation as well. More details about the climate of the model are given in Mik07.

In "Appendix" the stability of the model in standard perturbation experiments is discussed and compared to the outcome from a model intercomparison project.

\subsection{The ice sheet model}

The ISM SICOPOLIS used for this study is a 3D thermomechanical (that is, it includes the dependence of the flow of ice on temperature) model that has been applied to several studies of past, present and future climate (Greve 1997, 2000a, b; Greve et al. 1999; Calov and Marsiat 1998; Savviin et al. 2000).

The ISM integrates the time-dependent equations governing ice sheet extent and thickness, ice velocity, temperature, water content and age for any specific grounded ice as a response to external forcing. This is given by surface temperatures, surface mass balance, sea level and geothermal heat flux. 
The model treats ice as an incompressible, heat-conducting, power-law fluid with stress-strain rate relation:

$\boldsymbol{D}=E A\left(T^{\prime}\right) f(\sigma) \boldsymbol{T}^{R}$

where $\boldsymbol{D}$ is the strain-rate tensor, $\boldsymbol{T}^{\boldsymbol{R}}$ is the frictional stress tensor, $\sigma$ is the effective shear stress, and $f(\sigma)$ is the creep response function. The flow rate factor $A\left(T^{\prime}\right)$ is defined as a function of $T^{\prime}$, the difference between the temperature and the pressure melting temperature. The enhancement factor $E$ stands for the changes in ice viscosity due to impurities or induced anisotropy of the ice (Paterson 1991), being $E=1$ the value for pure ice. The frictional stress tensor differs from the full stress tensor in that the hydrostatic component is subtracted. The effective shear stress is defined as a function of the components of the frictional stress tensor:

$\sigma=\sqrt{\frac{1}{2} \operatorname{tr}\left(\boldsymbol{T}^{\boldsymbol{R}}\right)^{2}}$

where tr indicates trace, e.g., the sum of the elements of the main diagonal.

The creep response function is defined as

$f(\sigma)=\sigma^{n-1}$

with $n=3$ (Glen's law).

No sliding is prescribed if basal ice temperature is lower than pressure melting temperature. If basal ice is at melt temperature, a Weertman-type sliding law is applied, following Calov (1994) and Calov and Hutter (1996):

$\boldsymbol{v}_{\boldsymbol{b}}=-C_{\mathrm{sl}} H\|\operatorname{grad} h\|^{2} \operatorname{grad} h$

where $v_{\boldsymbol{b}}$ is basal velocity, $C_{\mathrm{sl}}=10^{5}$ year $^{-1}$ (Greve 1997) is the sliding coefficient, $H$ is ice thickness, and $\operatorname{grad} h$ is the topographic gradient. The effect of sediment at the glacier bed is not considered.

The model equations are subjected to the Shallow Ice Approximation (SIA), which means that they are scaled with respect to the ratio of typical thickness to typical length, and only first-order terms are kept. The SIA yields hydrostatic pressure conditions and ice flow governed by the gradients of pressure and the shear stresses in horizontal planes. Ice shelves cannot be modelled with this approximation and are not included in this ISM.

Isostatic depression and rebound of the lithosphere due to the ice load are modelled by a local lithosphere relaxing asthenosphere model (Le Meur and Huybrechts 1998), which balances the downward ice weight and the upward buoyancy force exerted by the asthenosphere on the elastic lithosphere. To include the viscosity of the asthenosphere a time lag of $\tau_{\mathrm{V}}=3,000$ years is applied.

For the geothermal heat flux, a global mean value of $55 \mathrm{~m} \mathrm{Wm}^{-2}$ (Sclatter et al. 1980) has been taken for the northern hemisphere domain. In the southern hemisphere the same value has been used, except for Antarctica, where a 2-D map of geothermal heat flux has been implemented in order to account for the different age of the bedrock in the East and West sections. The values taken are $70 \mathrm{~m}$ $\mathrm{Wm}^{-2}$ for the West AIS and $45 \mathrm{mWm}^{-2}$ for the East AIS (Sclatter et al. 1980). A transition area between these two regions of width $1,000 \mathrm{~km}$ is defined parallel to the Transantarctic Mountains in order to assure a smooth transition in the basal thermal forcing.

The model grid is built on a polar stereographic projection. The model domain consists of two sub-domains covering the entire globe except the tropical areas, from approximately $20^{\circ} \mathrm{N}(\mathrm{S})$ to the North (South) Pole. The horizontal resolution is $80 \mathrm{~km}$. This is a relative coarse resolution compared to the resolution used in other studies of anthropogenic-forced changes of the mass balance of the GrIS or the AIS performed with coupled models (e.g. Huybrechts et al. 2002; Fichefet et al. 2003; Ridley et al. 2005; Driesschaert et al. 2007). In these studies the model components are simpler and/or the domain of the ice sheet model was constrained to the regions of Greenland and/or Antarctica. In our study, however, the domain is quasiglobal (tropical regions are excluded for obvious reasons), the atmospheric and ocean components are GCMs, and multiple simulations have been performed with different scenarios of greenhouse gas forcing. This combined with the fact that the ESM has been designed for the performance of long simulations imposes a limit to the resolution of the ice sheet model due to computational cost. The vertical resolution is 21 levels for the ice column, with increasing resolution with depth, and 11 levels for the bedrock directly underneath.

\subsection{Coupling of the ISM to the climate model}

The atmospheric forcing of the ISM consists of seasonal 2-m atmospheric temperatures and precipitation rates. Annual mean temperatures from CTRL are too cold in Greenland by approximately $7 \mathrm{~K}$, due to underestimation of cloud cover in the Artic region. In the southeast coast temperatures are too warm. The spatial pattern of temperature agrees well with observations, with colder temperatures in the interior. In Antarctica, the pattern of temperature agrees with observations as well, with the coldest temperatures in the interior of East Antarctica and the highest temperatures in the Antarctic Peninsula. Annual mean temperatures are approximately $4 \mathrm{~K}$ lower than observations in the interior of East Antarctica and $3 \mathrm{~K}$ lower in West Antarctica. Temperatures are overestimated in the area of the big ice shelves of the Ross and Weddell Seas, because ice shelves are not modelled within the ISM. In Greenland, the pattern of precipitation follows the 
observed pattern of highest precipitation rates in the southeast, decreasing precipitation rates with height, and a minimum over the northwest. The amount of precipitation is overestimated in the Arctic region, and especially in central Greenland due to the smooth representation of the topography. Total precipitation over the ice sheet amounts to $657 \times 10^{12} \mathrm{~kg} \mathrm{year}^{-1}$. The figure given in Church et al. (2001) for total accumulation over the GrIS is $520 \times 10^{12} \mathrm{~kg} \mathrm{year}^{-1}$. This overestimation of precipitation over ice sheets is a common problem of coarse resolution AGCMs (Ohmura et al. 1996). The pattern of precipitation over Antarctica follows the observed pattern as well: lowest precipitation rates occur over the interior of the Antarctic Plateau in East Antarctica, and higher rates take place in West Antarctica, with maximal rates in the Antarctic Peninsula. The amount of precipitation is overestimated in the interior of Antarctica due to the insufficient representation of the topographic barrier to the penetration of precipitation, as it happens with Greenland.

Due to the bias in the climate simulated over the ice sheets, a correction has been applied for both the 2-m temperatures and precipitation rates. The use of "corrected" forcing is a commonly used-although far from ideal-approach in many projections of the future mass balance of ice sheets (Huybrechts et al. 2002; Ridley et al. 2005; Driesschaert et al. 2007) and has been for more than a decade the standard approach in coupled AOGCMs. Instead of using the raw atmospheric fields, anomalies from the AGCM are superimposed on the present-day climatology taken from ERA40 (Uppala et al. 2005). Precipitation anomalies have been preferred to corrections based in the ratio between reanalysis and model data in order to conserve water in the ESM. These corrections applied on the atmospheric forcing of the ice sheets will be referred to in the following as "flux corrections".

To account for the differences in the reference topography of the fields from the ERA40 climatology and the atmospheric data from the AGCM, two corrections have been applied to the near-surface temperature and precipitation fields. For the near-surface temperatures a linear height correction with the environmental lapse rate $-6.5 \mathrm{~K} \mathrm{~km}^{-1}$ has been applied. For precipitation rates $P$, an exponential height-desertification correction has been applied. Precipitation rates are reduced by $50 \%$ per kilometer above the height $h_{0}=2 \mathrm{~km}$ (Budd and Smith 1979):

$P(h)= \begin{cases}P_{\mathrm{GCM}} \exp \left(\gamma_{p}\left[\max \left(h_{\mathrm{GCM}}, h_{0}\right)-h_{0}\right]\right), & h \leq h_{0} \\ P_{\mathrm{GCM}} \exp \left(\gamma_{p}\left[\max \left(h_{\mathrm{GCM}}, h_{0}\right)-h\right]\right), & h>h_{0}\end{cases}$

where $h$ is the height at which precipitation rates are calculated in the ice sheet model, $P_{\mathrm{GCM}}$ is the precipitation rate from the AGCM, $h_{\mathrm{GCM}}$ is the height in the AGCM, and $\gamma_{\mathrm{p}}=-0.6931 \mathrm{~km}^{-1}$ is the coefficient from the exponential law.

Seasonal precipitation rates $P$ are converted into seasonal accumulation rates $S$ by an empirical formulation (Marsiat 1994), which relates them to the seasonal nearsurface temperatures $T$ :

$S=P \times\left\{\begin{array}{cc}0, & T \geq 7^{\circ} \mathrm{C} \\ \left(7^{\circ} \mathrm{C}-T\right) / 17^{\circ} \mathrm{C}, & -10^{\circ} \mathrm{C} \leq T \leq 7^{\circ} \mathrm{C} \\ 1, & T \leq-10^{\circ} \mathrm{C}\end{array}\right.$

Surface melting is parameterised according to Calov (1994) following the degree-day model by Braithwaite and Olensen (1989). The melting rate $m$ is linearly coupled to the air-temperature excess above the melt temperature $T_{m}$ :

$m=\left\{\begin{array}{cc}\beta T_{C} & T_{C}>T_{\mathrm{m}} \\ 0 & \text { otherwise }\end{array}\right.$

where $T_{C}$ is the near-surface temperature and $\beta$ is the degree-day factor. A different $\beta$ is employed for the melting of snow, $\beta_{\text {snow }}=3 \mathrm{~mm}$ water equivalent (WE) day ${ }^{-1}{ }^{\circ} \mathrm{C}^{-1}$, and for the melting of ice, $\beta_{\text {ice }}=12 \mathrm{~mm}$ WE day ${ }^{-1}{ }^{\circ} \mathrm{C}^{-1}$ for the northern hemisphere and $\beta_{\text {ice }}=$ $8 \mathrm{~mm} \mathrm{WE}$ day $^{-1}{ }^{\circ} \mathrm{C}^{-1}$ for the southern hemisphere (Reeh 1991; Greve et al. 1999; Calov et al. 1998). The higher degree-day factor of ice compared to snow is due to the different albedos of snow and ice. The value $\beta_{\text {ice }}=8$ $\mathrm{mm} \mathrm{WE}$ day ${ }^{-1}{ }^{\circ} \mathrm{C}^{-1}$ is standard in studies of Greenland and Antarctica. The higher value for the northern hemisphere was obtained from calibration of the ISM against the Holocene evolution of northern hemisphere ice sheets (Greve et al. 1999).

Air temperatures are assumed to follow a sinusoidal annual cycle with amplitude equal to the difference between the summer and annual temperatures. Additional variations due to the diurnal cycle and changing weather conditions are treated as normally distributed statistical variations with standard deviation $\sigma_{\text {stat }}=5^{\circ} \mathrm{C}$ (Greve et al. 1999).

There is a simple parameterisation that accounts for refreezing. The ice-surface temperature $T_{\mathrm{S}}$ is assumed to be equal to the mean annual air temperature $T_{\text {ma }}$ unless the formation rate of superimposed ice, $M^{*}$, exceeds the icemelting rate, $M$. In this case, an empirical firn-warming correction due to latent-heat release (Reeh 1991) is applied:

$T_{\mathrm{S}}=T_{\mathrm{ma}}+\max \left\{\mu_{\mathrm{fwc}}\left(M^{*}-M\right) ; 0\right\}$

with the firn-warming correction coefficient $\mu_{\mathrm{fwc}}=$ 24.206 ${ }^{\circ} \mathrm{C} \mathrm{m}^{-1}$ year.

Due to the differences in the size of the atmospheric grid (T21) and the ice sheet grid $(80 \mathrm{~km})$, a downscaling technique is needed. The atmospheric data is bi-linearly interpolated onto the ice sheet model grid, and height 
differences are accounted for using the same algorithm as for the "flux corrections". The time step for the ISM as well as the coupling time step is 1 year.

The ice sheet model provides topography and albedo changes via changes in the glacier mask to the atmosphere and freshwater fluxes to the ocean. As the AGCM can treat land points only either as glaciers or as ice-free land points, an atmospheric model grid point (resolution T21) is defined as glacier point if at least $50 \%$ of its area is glaciated according to the interpolated ice-covered area from the ISM grid. Freshwater fluxes from the ice sheets are treated differently in the case of being supplied to the ocean as ice and in the case of being supplied as liquid water. The first case corresponds to iceberg calving and basal melting due to ocean heat supply, the second case to surface melting and basal melting due to geothermal heat fluxes. The distinction is made in order to account for the heat exchange between calved icebergs and floating ice shelves and the ocean when the former melt.

\subsection{Initialization of the model and control ice sheets}

For the initialization of the ESM, a 10,000-year spin-up simulation has been performed. The flux corrections for the atmospheric forcing of the ISM were calculated during this simulation.

For the initialization of the ISM, two glacial cycles have been simulated with a simple climatic forcing. A time-dependent temperature anomaly from the central Greenland GRIP ice core (Dansgaard et al. 1993) for the northern hemisphere and from the VOSTOK ice core (Jouzel et al. 1993, 1996) for the southern hemisphere has been superimposed on the present-day climatology from ERA40 (Uppala et al. 2005) for the temperature forcing of the ISM.

A linear relationship between temperature and precipitation changes has been used for precipitation forcing (Greve et al. 1999). For sea level forcing the SPECMAP $\delta^{18} \mathrm{O}$ record (Imbrie et al. 1984) is used via the conversion (Greve et al. 1999)

$z_{\mathrm{sl}}(\mathrm{m})=-34.83 \mathrm{~m} \cdot\left(\delta^{18} \mathrm{O}(\%)+1.93\right)$

where $z_{\mathrm{sl}}$ is the sea level expressed in meters.

A 2,250-year-long control simulation (CTRL) corresponding to pre-industrial climate was performed in order to be used as reference simulation for the anthropogenic climate change simulations. The mean simulated concentration of $\mathrm{CO}_{2}$ is 279.5 ppmv.

The simulated northern hemisphere ice sheets from CTRL have an area of $2.15 \pm 0.02 \times 10^{6} \mathrm{~km}^{2}$. These ice sheets are located mainly on Greenland. Other glaciated areas are simulated in Svalbard, Iceland, Baffin Island,
Ellesmere Island and the Rocky Mountains. These glaciated areas are placed at locations, which correspond to observed glaciers and ice caps.

According to Church et al. (2001), the area of the GrIS is $1.71 \times 10^{6} \mathrm{~km}^{2}$, and its volume corresponds to $7.2 \mathrm{~m}$ sea level equivalent (SLE). The simulated northern hemisphere ice sheets have a volume of $8.6 \mathrm{~m}$ SLE. The main differences between the topography of the control GrIS and the measurements from ETOPO5 (ETOPO5 1988) are found in northeast Greenland, where thickness anomalies are as large as 500-800 m (Fig. 1). These differences in northeast Greenland explain most of the difference of volume between the simulated and measured ice sheet. The middle part of the ice sheet is 100-200 m lower than observed.

In the southern hemisphere, all simulated glaciated points are placed on Antarctica. The simulated area of the AIS $\left(12.70 \pm 0.02 \times 10^{6} \mathrm{~km}^{2}\right)$ exceeds by $3 \%$ the measured area (Church et al. 2001). Its volume $(66.94 \pm 0.19 \mathrm{~m} \mathrm{SLE})$ is $9 \%$ bigger. All numbers given here correspond only to grounded ice, that is, the area and volume of the ice shelves have not been taken into account. The ice excess is placed in West Antarctica and the area of the Amery Ice Shelf (Fig. 1). The grounding line is correctly located in most of the margins. In the area of the Ronne Ice Shelf it is slightly misplaced towards the interior of the continent. The simulated area of grounded ice in the Antarctic Peninsula is more extended than the observed.

In general, the simulated ice sheets are in good agreement with observations. The described discrepancies are due to the combination of several factors, such as the very crude atmospheric forcing imposed during the spin-up, the coarse resolution of the ISM, and the incomplete representation of the processes taking place at the grounding line.

\section{Simulations setup and changes in atmosphere and ocean}

\subsection{Simulations setup}

Two different sets of anthropogenic climate change simulations have been performed with the ESM. The first set consists of stabilisation scenarios where the atmospheric concentration of $\mathrm{CO}_{2}$ is increased by $1 \%$ per year, until $2 \times$, $3 \times$ and $4 \times$ pre-industrial levels are achieved, at years 70 , 105 and 140, respectively. Those experiments have a length of 1,000 years. A detailed description of carbon cycle interactions with climate in these stabilisation scenario simulations is given in Winguth et al. (2005). For the second set of experiments, carbon emissions instead of $\mathrm{CO}_{2}$ concentrations have been prescribed, as follows: for 
Fig. 1 a Simulated topography of the GrIS from CTRL (m). b Simulated topography of the AIS from CTRL (m). Comparison of the topography (m) of the simulated CTRL ice sheets with measurements from ETOPO5 (ETOPO5, 1988): c GrIS and $\mathbf{d}$ AIS. The purple line delimits the area with changes exceeding $500 \mathrm{~m}$. The black line of $\mathbf{a}$ and $\mathbf{c}$ corresponds to the ETOPO5 isoline for $0 \mathrm{~m}$ height, while the black line of $\mathbf{b}$ and $\mathbf{d}$ corresponds to the grounding line of the measured ice sheet a Modelled GrIS
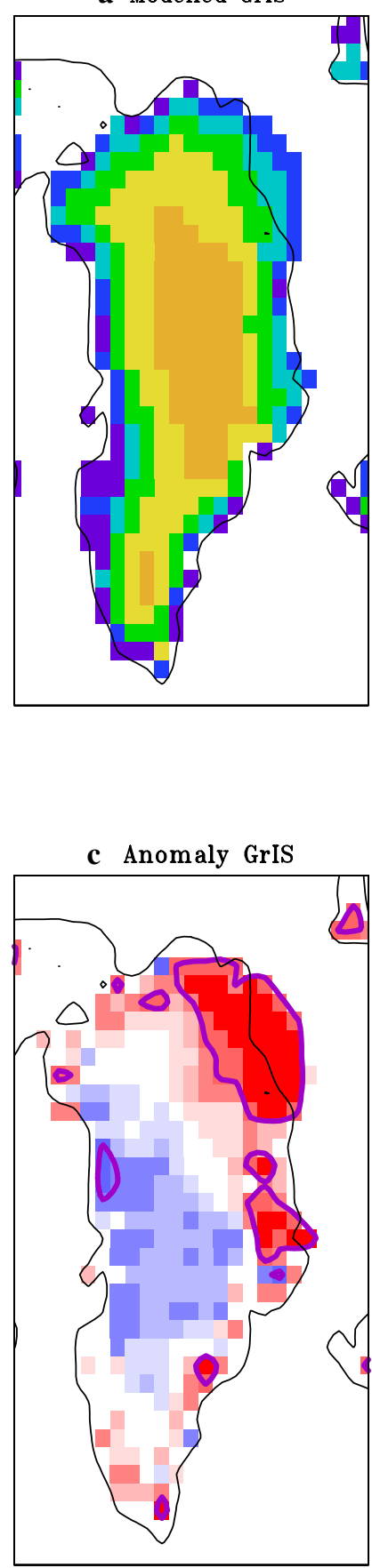

b Modelled AIS
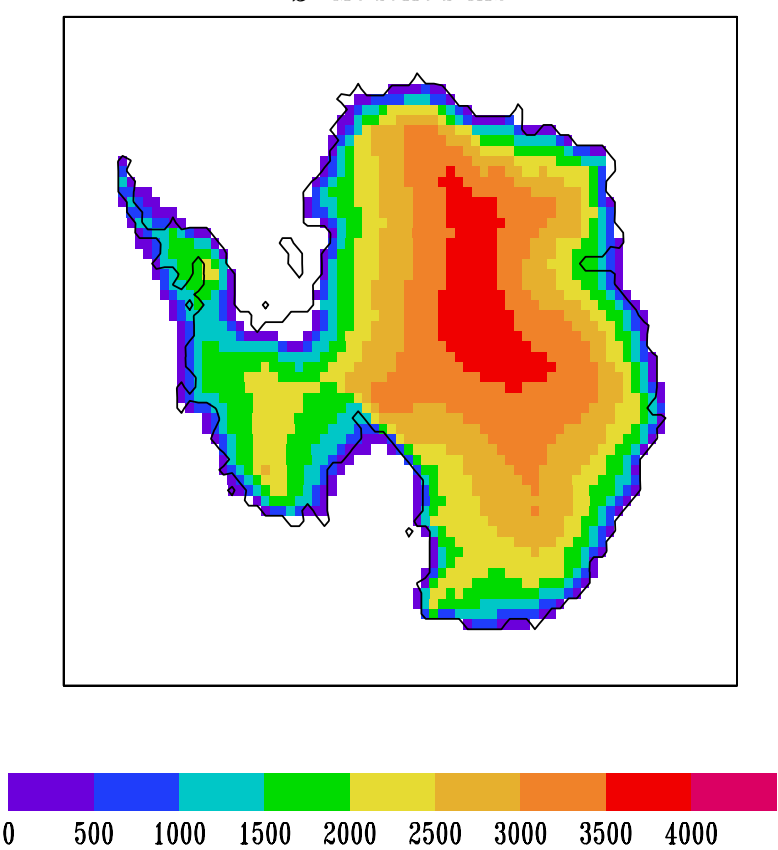

d Anomaly AIS
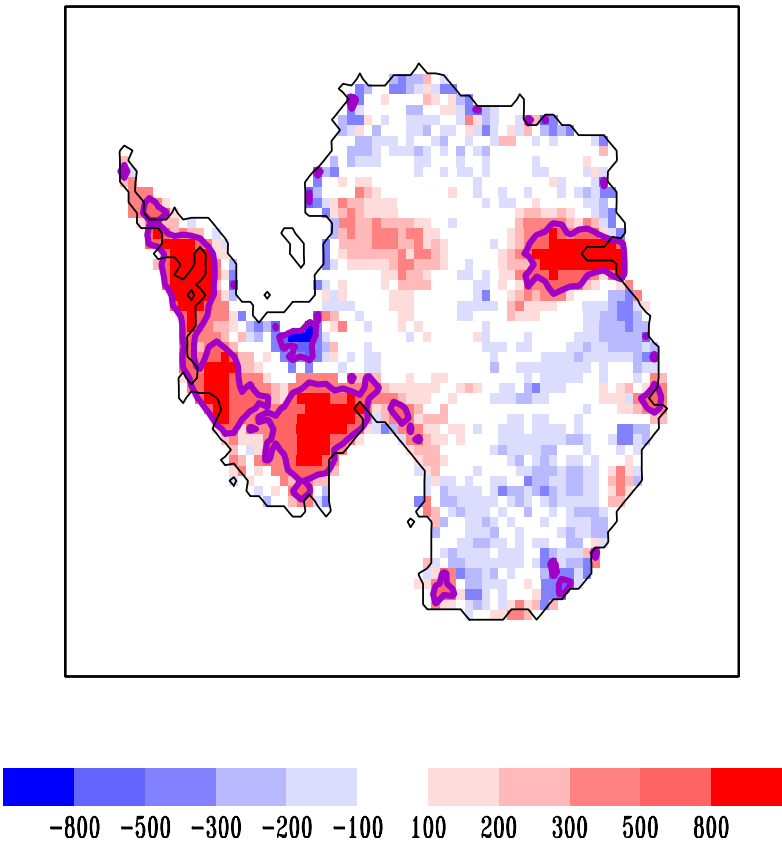

the calendar years 1750-2000 historical emissions (Marland et al. 2005; Houghton and Hackler 2002) have been used, followed by several IPCC emission scenarios for 2000-2100 (Nakicenovic et al. 2001), and an exponential decay of emissions (with a time constant of 150 years) for subsequent years. Other greenhouse gases like methane and aerosols have not been taken into account. The outcome of these experiments has been described in Mik07. The present paper will focus on the output of the stabilisation simulations and two multi-millennia simulations for the emission scenario A2.

For each scenario, two simulations have been performed: one where the feedbacks from the ice sheets are passed to the other components (two-way coupling) and another one where those feedbacks are ignored (one-way coupling). The former simulations will be referred to as $2 \times, 3 \times, 4 \times$ and $\mathrm{A} 2$, and the later as $2 \times \_1 \mathrm{w}, 3 \times \_1 \mathrm{w}$, $4 \times \_1 \mathrm{w}$ and A2_1w, with *_1w meaning one-way 
coupling. The comparison between those two sets allows the identification of climatic changes induced by the ice sheets.

An additional simulation CTRL_NOGr was performed in order to investigate whether the GrIS is bi-stable and the climatic impact of the disappearance of the GrIS in a preindustrial climate. The setup of this simulation is identical to CTRL, except for the initial GrIS, which is reduced to a small cap in the southern part of Greenland.

All experiments are summarised in Table 1.

\subsection{Climate change}

The mean global temperature increases in all simulations. The increase in the mean global near-surface temperature is 2.1 $\mathrm{K}(2 \times), 3.2 \mathrm{~K}(3 \times)$ and $4.2 \mathrm{~K}(4 \times)$ at the end of the simulations (Fig. 2a). Mik07 estimated the equilibrium value of the warming in surface air temperature of this ESM to be approximately $2.3 \mathrm{~K}$ per $\mathrm{CO}_{2}$ doubling. In the AR4 IPCC report (Meehl et al. 2007) a mean sensitivity of $3 \mathrm{~K}$ for doubling of $\mathrm{CO}_{2}$ is given. This value, however, has been derived from AGCMs coupled to mixed-layer oceans. In our coupled model changes in ocean overturning lead to little warming or cooling in the North Atlantic and in the Southern Ocean. As this cannot take place in the standard doubling $\mathrm{CO}_{2}$ simulations, the value derived from the coupled model is lower than the one that would have been derived from an AGCM/mixed layer ocean setup. A simple estimate yields a climate sensitivity of approximately $2.6 \mathrm{~K}$ per $\mathrm{CO}_{2}$ doubling for our atmospheric component, which is somewhat lower than the best estimate of $3 \mathrm{~K}$ from the AR4 IPCC report (Meehl et al. 2007), but well within the range of uncertainty $(2-4.5 \mathrm{~K})$.
The rate of global temperature increase is strongest when the atmospheric $\mathrm{CO}_{2}$ concentration is still rising. After stabilisation, global temperatures continue rising due to the delay associated with the storage of heat by the ocean (Voss and Mikolajewicz, 2001). In the $4 \times$ simulation a period of slight global mean temperature decrease occurs between years 200 and 400 . This is, as it will be shown in the next paragraph, related to significant changes in global ocean circulation.

Reduced formation of North Atlantic Deep Water (NADW) and a decline in the strength of the meridional overturning circulation take place in all simulations (Fig. 2b). In $2 \times$ and $3 \times$ this reduction in the strength of the NAMOC is modest and it reaches values only slightly lower than those of the control simulation after a century from the time of maximum reduction at year 150 in $2 \times$ and at years $300-400$ in $3 \times$. In $4 \times$, on the contrary, the strength of the NAMOC is steadily decreasing with time, until a state without a NADW cell is reached by year 400 . It does not recover by the end of the simulation. The cause of this reduction in the NAMOC and the role played in it by the ice sheets is analysed in Sect. 5 of this paper.

The 2D pattern of temperature change (Fig. 3) shows stronger warming over the continents than over the oceans for all simulations, as it is the case in the models from the IPCC AR4 (Sutton et al. 2007). Arid regions show a stronger warming, in common with the analysis of Sutton et al. (2007). Northern high latitudes also experience a stronger warming than other regions, due to the positive snow and sea ice albedo feedback. This effect is called "polar amplification" (Holland and Bitz 2003; MassonDelmotte et al. 2006). Over the North Atlantic either weak warming or, in the case of $4 \times$, net cooling takes place, in connection to the changes in the NAMOC. This can be

Table 1 List of experiments

\begin{tabular}{|c|c|c|}
\hline Name & Length & Description \\
\hline CTRL & $0-2250$ & Pre-industrial concentration of $\mathrm{CO}_{2}$ (prognostic) \\
\hline $2 \times$ & $0-1000$ & $1 \%$ increase of $\mathrm{CO}_{2}$ until stabilisation at $2 \times \mathrm{CO}_{2}$ \\
\hline $3 \times$ & $0-1000$ & $1 \%$ increase of $\mathrm{CO}_{2}$ until stabilisation at $3 \times \mathrm{CO}_{2}$ \\
\hline $4 \times$ & $0-1000$ & $1 \%$ increase of $\mathrm{CO}_{2}$ until stabilisation at $4 \times \mathrm{CO}_{2}$ \\
\hline *_1w & $0-1000$ & One-way coupling: feedbacks ice sheets-climate not included \\
\hline $3 \times \_$FIXTOP & $0-1000$ & $\begin{array}{l}\text { As } 3 \times \text {, with fixed topography: the simulation does not allow for the } \\
\text { height albedo feedback or changes in the ice flux }\end{array}$ \\
\hline $3 \times \_$FIXADV & $0-1000$ & As $3 \times$, with fixed advection: velocities are prescribed as in CTRL \\
\hline $\mathrm{A} 2$ & Calendar years $1750-9000$ & $\begin{array}{l}\text { Carbon emissions prescribed according to: (1750-2000) historic, } \\
\text { (2001-2100) IPCC SRES A2, (2100-9000) exponential decay with } \\
\text { a time constant of } 150 \text { years }\end{array}$ \\
\hline A2_1w & $\begin{array}{l}\text { Calendar years } 1750-7000 \text { (for } 7000-9000 \text { ice sheet } \\
\text { model run offline with atmospheric forcing from } 6000- \\
7000 \text { ) }\end{array}$ & $\begin{array}{l}\text { As A2, but changes in freshwater fluxes, glacier mask and topography } \\
\text { from ice sheet model not passed to other components }\end{array}$ \\
\hline CTRL_NOGr & $0-1000$ & As CTRL, without GrIS as initial condition \\
\hline
\end{tabular}



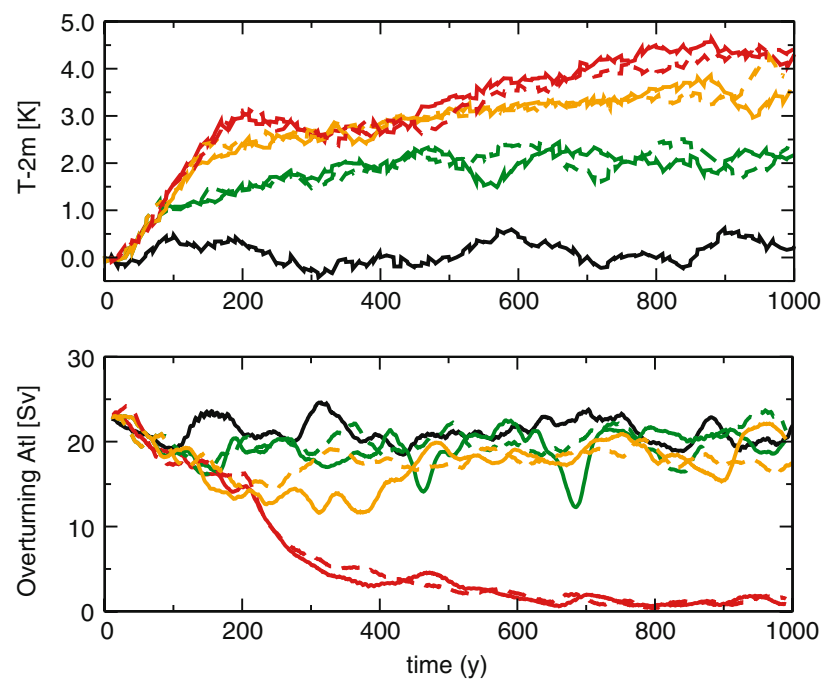

Fig. 2 a Changes in mean annual near-surface (2-m height) temperature $(\mathrm{K})$ for the $2 \times$ (green lines), $3 \times$ (yellow), $4 \times($ red $)$ and CTRL (black) relative to CTRL mean. Dashed lines represent the simulations *_1w where the feedbacks ice sheets-climate are not included. b Strength of the NAMOC at $30^{\circ} \mathrm{N}$ and at $1500 \mathrm{~m}$ depth (Sv). All timeseries are 20-year running means

explained by the complete collapse of the NADW-cell and the associated reduced oceanic heat transport. Due to the presence of sea ice close to the deepwater formation region, sea ice effects (albedo and insulation) strongly amplify the local cooling. A similar cooling for completely collapsed NADW-cells in a greenhouse climate has been reported by Schaeffer et al. (2004). Other simulations with stronger global mean warming where a complete collapse of NADW formation is simulated like, e.g., Manabe and Stouffer (1994) do not simulate a regional cooling, but only a region with minimal warming.

The hydrological cycle is enhanced in all greenhouse simulations. In the North Atlantic, smaller anomalies/ reduction of precipitation are seen associated with the low warming/net cooling signal in this region. The model shows a mean increase of global mean precipitation of $5.1 \%$ for a $\mathrm{CO}_{2}$ doubling (estimated from the ESM), compared to an average of $6.6 \%$ from the IPCC 2001 report (Houghton et al. 2001).

\section{Evolution of global ice sheets and sea level}

\subsection{Evolution of the Greenland ice sheet}

Regional climate changes in and close to Greenland in these simulations are the result of the combination of two effects: (1) a global signal associated with high global concentration of atmospheric $\mathrm{CO}_{2}$, and (2) a regional signal associated with changes in the strength of the NAMOC and
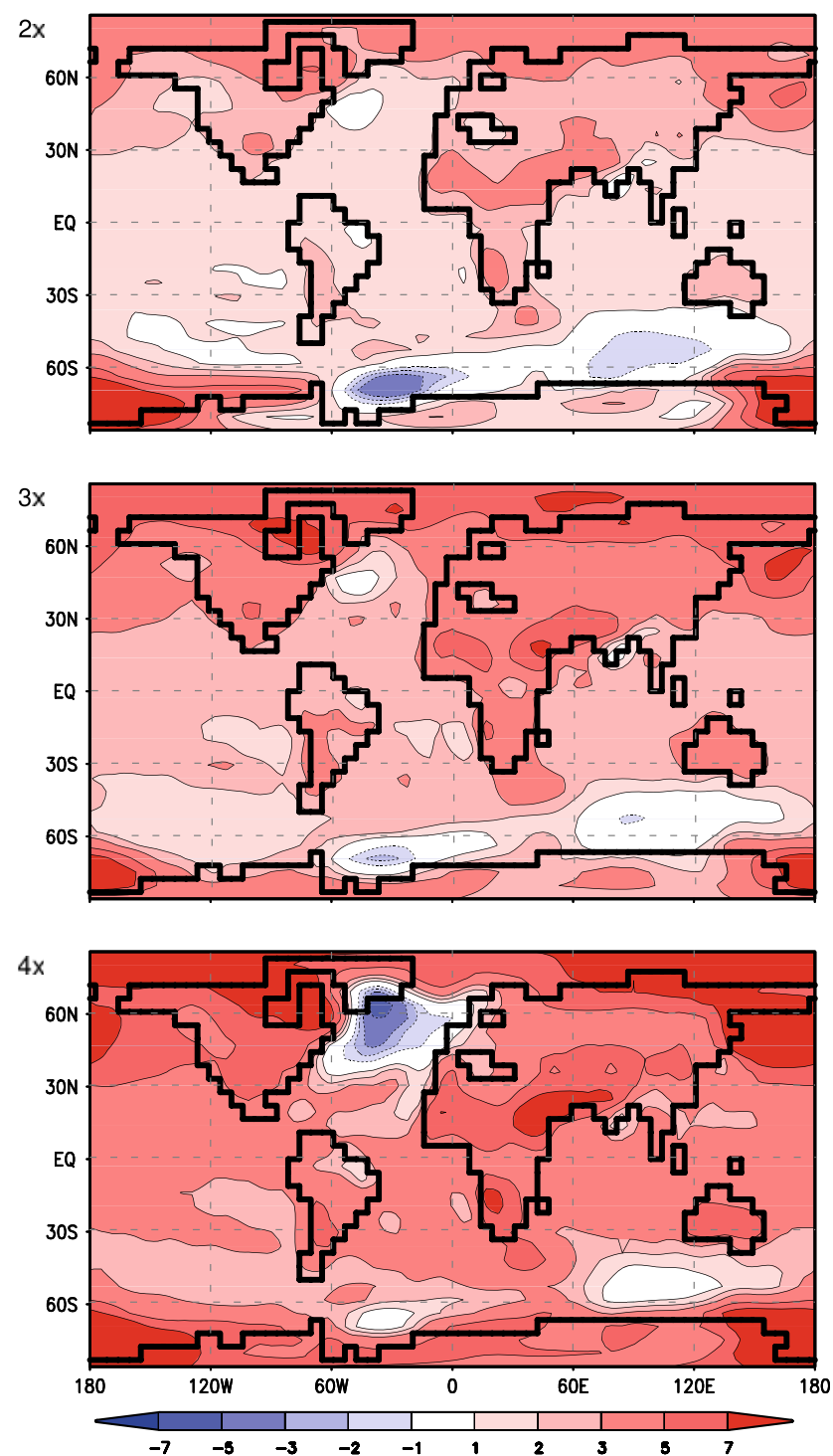

Fig. 3 Global distribution of changes in the annual near-surface air temperature $(\mathrm{K})$ for the simulations $2 \times, 3 \times$ and $4 \times$ compared to CTRL. Years 900-1000

associated meridional heat transport. The first signal is warm and wet; the second one either reduces the magnitude or reverses the sign, depending on the scenario, of the temperature and precipitation changes caused by the high concentration of greenhouse gases. The combination of the signals (1) and (2) produces a meridional gradient of temperature change over Greenland, with larger positive anomalies in the north and smaller/negative ones in the south (Fig. 4). In the simulation $4 \times$, in which the NAMOC collapses completely, this gradient is strongest: lower temperatures than in CTRL occur in the southern part of Greenland and higher temperatures occur in the northern half. Precipitation changes behave similarly to temperature changes. While the GrIS receives more precipitation everywhere in $2 \times$ and $3 \times$ than in CTRL, in $4 \times$ the pattern 
Fig. 4 Changes in the summer (JJA) temperature (K) over Greenland with respect to CTRL averaged over years 900 1000. The differences also include the effect of modified topography in the greenhouse gas simulations
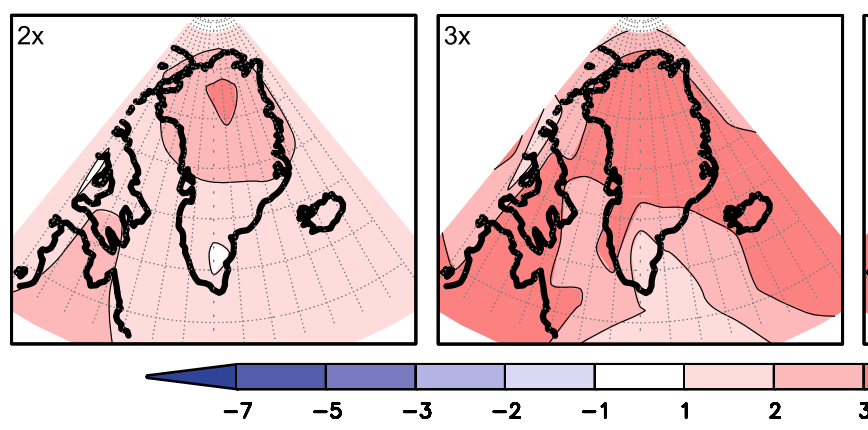

of precipitation changes shows a strong gradient over the ice sheet. Less precipitation falls on the southeast of the GrIS, while other parts receive more than in CTRL (not shown).

The integral volume of the GrIS decays in all the stabilisation scenario simulations $2 \times, 3 \times$ and $4 \times$ (Fig. 5a). By the end of the simulations, the loss of volume is equivalent to a sea level rise of $25 \mathrm{~cm}$ in $2 \times, 1 \mathrm{~m}$ in $3 \times$ and $40 \mathrm{~cm}$ in $4 \times$. The loss of mass is significantly higher in the simulation $3 \times$ than in $4 \times$, although the signal of global warming is stronger in $4 \times$, as shown above. The reasons for the lower loss of total mass in $4 \times$ are to be found in the
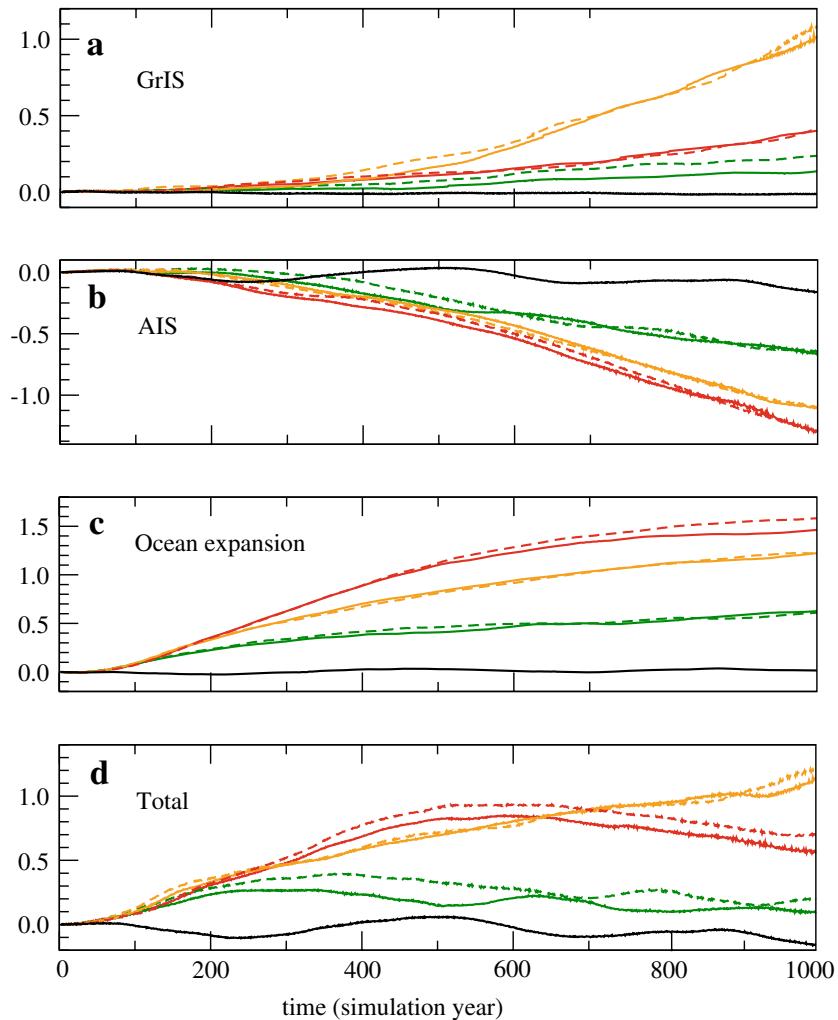

Fig. 5 Time series of sea level changes (m) in the stabilisation simulations $2 \times$ (green lines), $3 \times$ (yellow lines) and $4 \times($ red lines $)$ : a contribution from the GrIS, b contribution from the AIS, c contribution due to ocean thermal expansion, $\mathbf{d}$ net sea level changes. Dashed lines represent the simulations *_1w regional climate change over Greenland. In $4 \times$, the location of the centre of the negative temperature signal associated with the collapse of the NAMOC is located not far from the southeast coast of Greenland. The climate of the GrIS in $4 \times$ is colder than in CTRL in the southern third of Greenland, and colder than in $3 \times$ for the rest. Consequently, melting rates are much higher in $3 \times$ than in $4 \times$ and a stronger decay of the GrIS occurs in $3 \times$. The area of the GrIS does not change very much (Fig. 6). By the end of $2 \times$, only some isolated grid boxes in the ice sheet model (the size of each grid box is approximately $80 \mathrm{~km} \times 80$ $\mathrm{km})$ have become ice-free. In $3 \times$, the strongest changes occur at the eastern margin in the middle part of the island. In $4 \times$, while some isolated points become ice-free at the north of the ice sheet as they do in $3 \times$ as well, some others experience the opposite transition in the south, due to reduced melting rates.

By the end of the simulations, $2 \times$ and $3 \times$ show a similar pattern of $2 \mathrm{D}$ thickness changes (Fig. 6), with reduced thickness in the margins of the ice sheet due to increased melting rates, and increased thickness in part of the interior

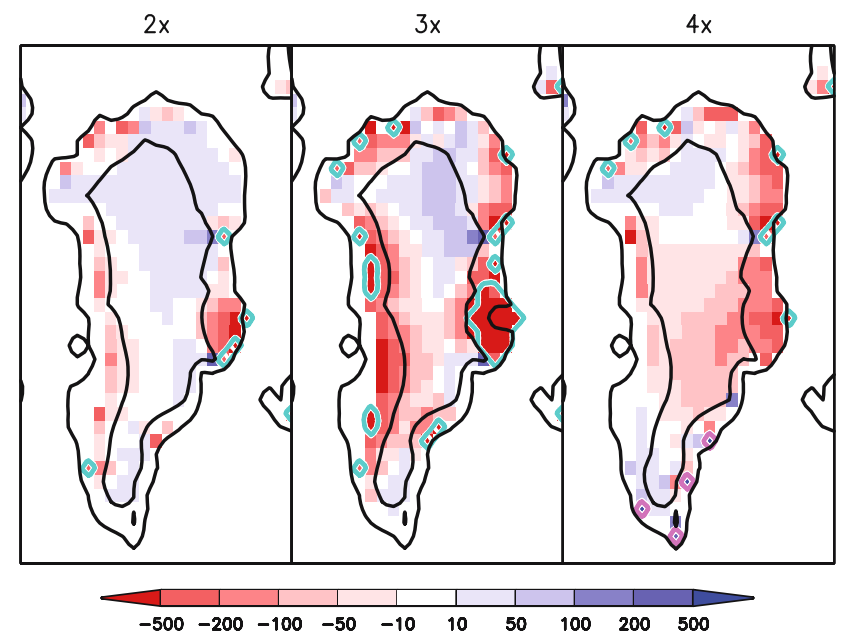

Fig. 6 Changes in ice thickness $(\mathrm{m})$ and grounding line position (blue line area becoming ice-free, pink line area becoming iced) in the GrIS for the period $900-1000$ for the simulations $2 \times, 3 \times$ and $4 \times$ minus CTRL. In black contour lines for heights $z=0 \mathrm{~m}$ and $z=2,000 \mathrm{~m}$ 
due to enhanced snowfall. In $3 \times$, in most of the Greenland Plateau, at a height of more than $2,000 \mathrm{~m}$, the change in the surface mass balance, which is the change in snowfall minus the change in surface melting, is positive (Fig. 7). Nevertheless, an area of reduced thickness can be seen in the central part in the Plateau by the end of the simulation. This mismatch between the surface mass balance and the vertically integrated mass balance is explained by changes in the horizontal transport of ice. The transport of grounded ice, placed on land, as opposite to floating ice in ice shelves and glacier tongues, is mostly driven by gravity forces and follows the direction of the gradients of topography. Changes in surface mass balance, such as increased melting dominating at the margins and increased snowfall dominating in the interior, cause increased gradients of topography. These increased gradients cause increased

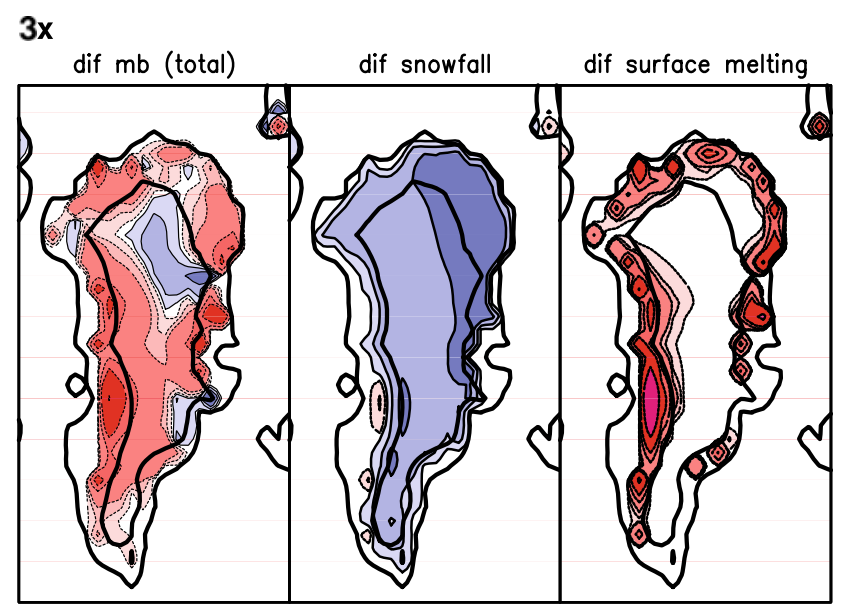

$4 x$
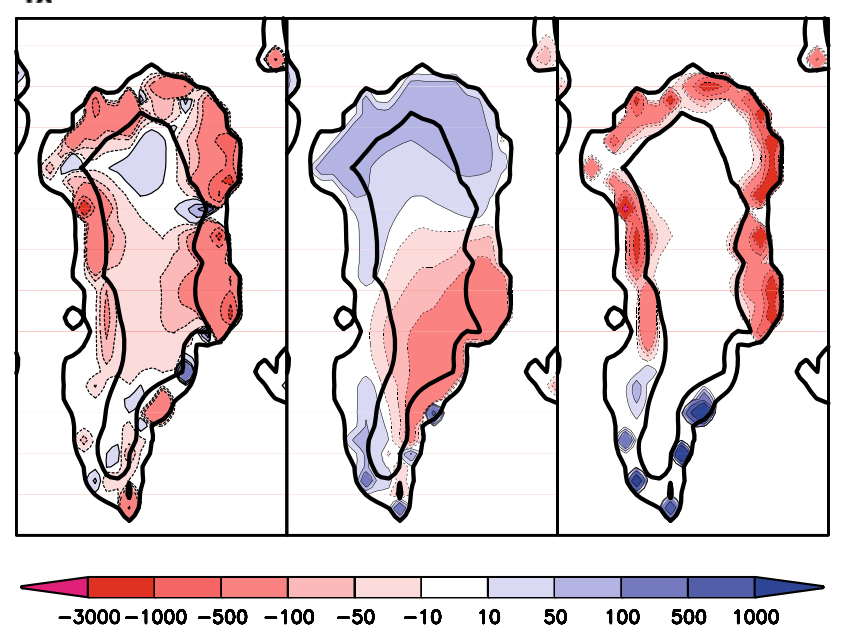

Fig. 7 Comparison of changes in the GrIS mass balance in $3 \times$ (upper panel) and $4 \times$ (lower panel) with respect to CTRL averaged over 900-1000. Units are millimeter of water equivalent (WE) per year. Left total mass balance change in ice column (net sum of all positive and negative terms including advection), middle surface accumulation change, right surface melting change. Contour lines for topographic heights $z=0 \mathrm{~m}$ and $z=2,000 \mathrm{~m}$ are shown in black transport of ice from the interior to the margins. In some cases, this increased transport becomes the dominant term of the mass balance, and regions of positive surface mass balance in the interior of the GrIS experience a total (vertically integrated) loss of mass.

By the end of the simulations, $4 \times$ shows a different $2 \mathrm{D}$ pattern of thickness changes than $2 \times$ and $3 \times$ (Fig. 6), with the middle part of the GrIS showing lower thickness than in CTRL due to reduced accumulation rates (Fig. 7), increased thickness in the southern margins due to reduced melting, and moderate thickness reduction in other margins due to a lesser increase in surface melting than in $3 \times$. The reduction with respect to CTRL in the snowfall rates in the middle part of the ice sheet is linked to the precipitation anomaly associated with the cold anomaly in the North Atlantic. The maximum reduction of snowfall takes place on the east coast. Consistent with the temperature forcing described before, the southern part of the GrIS has lower melting rates than in CTRL. In the rest of the low elevation areas, melting rates are higher than in CTRL but lower than in $3 \times$.

\subsubsection{The role of ice sheet dynamics}

Dynamical changes can play an important role in the mass balance of ice sheets on different time-scales. Here we will investigate two processes which can potentially contribute significantly to the total mass budget on the time scales which are the subject of this study: the height-feedback and changes in the horizontal transport of ice. The heightfeedback is a positive feedback for surface melting: since the height of an area of an ice sheet is lowered due to surface melting, the ice-surface temperatures increase due to the reduced height. The increase in temperatures lead to increased melting rates. The changes in the horizontal transport of ice are caused by changes in topographic gradients, triggered by changes in the surface mass balance, and changes in the thickness of the column of ice.

Modelling studies of changes in the mass balance of ice sheets not including a dynamic ice sheet, as calculations from snowpack models and calculations directly from the output of GCMs (Bugnion and Stone 2002; Wild et al. 2003; Wild and Ohmura 2000; Ohmura et al. 1996), do not include any of the two processes described above. In order to evaluate the importance of these processes to the total mass budget, two off-line simulations $3 \times$ FIXTOP and $3 \times$ FIXADV have been performed. In $3 \times$ _FIXTOP, the topography of the ice sheet is kept unchanged, as in the modelling approaches not including a dynamic ice sheet. Effects of the height-feedback and changes in horizontal transport are neglected. This approach could easily be adopted in AOGCMs by calculating the integrated mass 
balance at each grid point and adding the thickness change to the topography of the control integration. This could then-with some thresholds to estimate the conversion to ice-free points-be used to estimate time dependent changes in surface topography without using a dynamic ice sheet model. In $3 \times$ FIXADV (FIXADV stands for fixed advection), the topography of the ice sheet is allowed to change, but the transport at each grid point is kept constant throughout the simulation. Hence, only the height-feedback is included and not the effect of changes in the ice flux. $3 \times$ is taken as reference simulation, since it is the stabilisation scenario simulation where strongest changes occur to the GrIS.

The results of these simulations show that dynamical feedbacks become relevant compared to experiments with fixed topography ( $3 \times$ _FIXTOP) after 400 years, when the accumulated mass loss corresponds to $0.1 \mathrm{~m}$ SLE (Fig. 8). By the end of the simulation with fixed topography, $3 \times$ _FIXTOP, the GrIS has decayed $60 \%$ less than in $3 \times$. This indicates that the combined effect of the height feedback and the horizontal changes in the transport acts as a strong positive feedback on the decay of the ice sheet.

The feedback associated with changes in the horizontal transport changes its sign along the process of decay of the GrIS. This decay is faster in the simulation with fixed fluxes $3 \times$ FIXADV than in $3 \times$ until the ice sheet decays

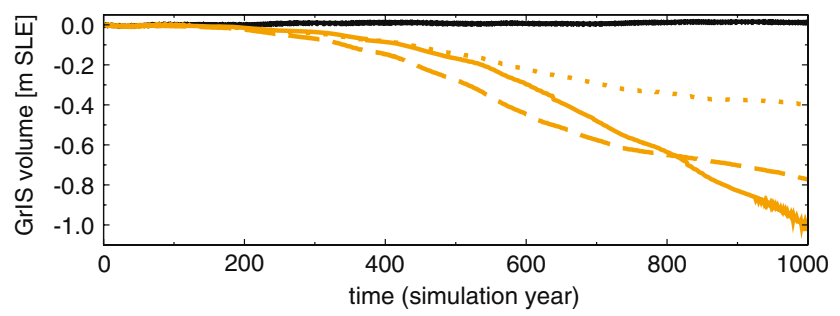

Fig. 8 Comparison of the GrIS volume decay for the simulations CTRL (black line), $3 \times$ (solid line), $3 \times$ _FIXTOP (dotted line), and $3 \times$ _FIXADV (dashed line) by approximately $8 \%$ of its original value. The initial lowering of the topography in the low marginal areas of the ice sheet in $3 \times$ triggers an increase on the horizontal flux of ice due to increased topographic gradients. This enhanced flux brings extra ice to the low elevation areas, increasing their topographic height. This, via the height-feedback, lowers the melting rates at the margins and acts as a negative feedback for the decay of the GrIS. The high-elevated areas originally in the accumulation area are lowered by this process of increased horizontal ice flux towards the margins of the ice sheet. The lowering of their topography is not sufficient, though, to bring a significant fraction of these regions to the ablation area. Later in the process of ice sheet decay, the reduction of height in these areas is sufficient to cause some summer melting in part of them. This additional surface melting from areas that initially did not experience any summer melting causes an increase in the total surface melting over the ice sheet. This changes the sign of the feedback caused by changes in the horizontal transport of ice to positive. By the end of the simulation, dynamical changes increase the mass loss of the GrIS by approximately $20 \%$.

\subsection{Evolution of the Antarctic ice sheet}

The volume of the AIS undergoes an increase approximately linear with time in all the greenhouse simulations. By the end of the simulations, the additional volume of water stored in the ice sheet is equivalent to a sea level drop of $50 \mathrm{~cm}$ in $2 \times, 1 \mathrm{~m}$ in $3 \times$, and $1.2 \mathrm{~m}$ in $4 \times$ (Fig. 5b). This shows a larger storage of water in the simulations with larger increases in the concentration of greenhouse gases. The model does not simulate any abrupt change in the evolution of the AIS in any of the simulations.

The 2D pattern of changes in ice thickness at the end of the simulations (Fig. 9) shows increased thickness all over
Fig. 9 Changes in ice thickness (m) and grounding line position (blue line area becoming icefree, pink line area becoming iced) in the AIS for the period 900-1000 for the simulations $2 \times, 3 \times$ and $4 \times$ minus CTRL. In black contour lines for heights $z=0 \mathrm{~m}$ and $z=2,000 \mathrm{~m}$

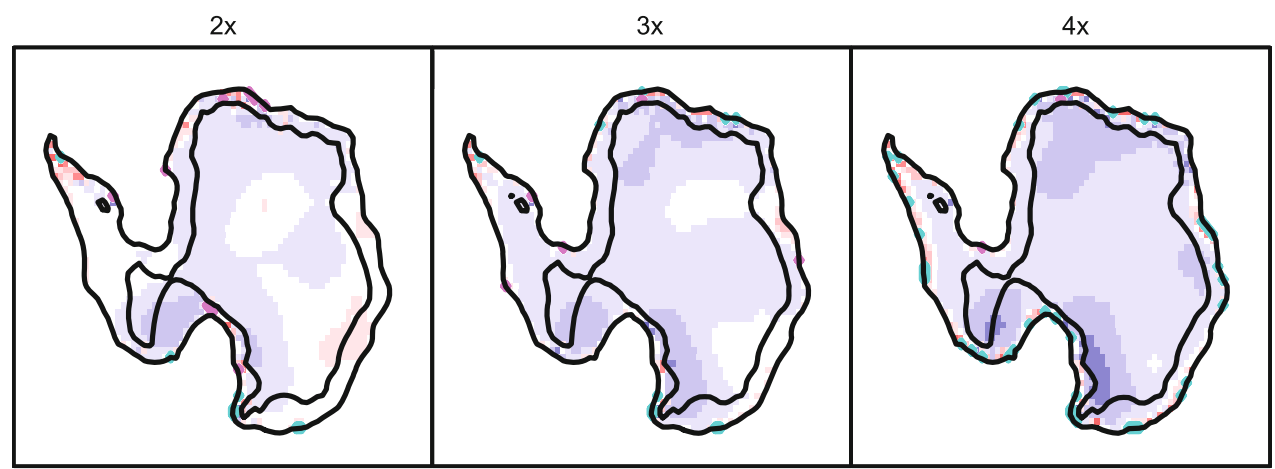


Fig. 10 Comparison of changes in the mass balance $\left(\mathrm{mm} \mathrm{WE}\right.$ year $\left.^{-1}\right)$ of the AIS for simulations $3 \times$ and $4 \times$ averaged over the period 900 1000. Left total change of mass in the ice column, middle accumulation change (snowfall), right surface melting change. In black contour lines for heights $z=0 \mathrm{~m}$ and $z=2,000 \mathrm{~m}$

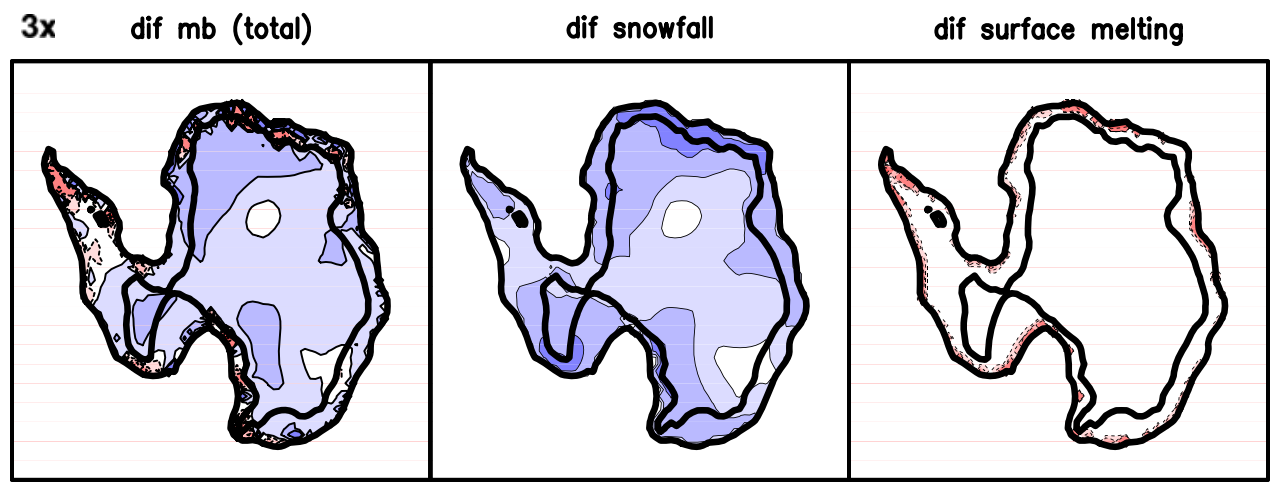

$4 x$
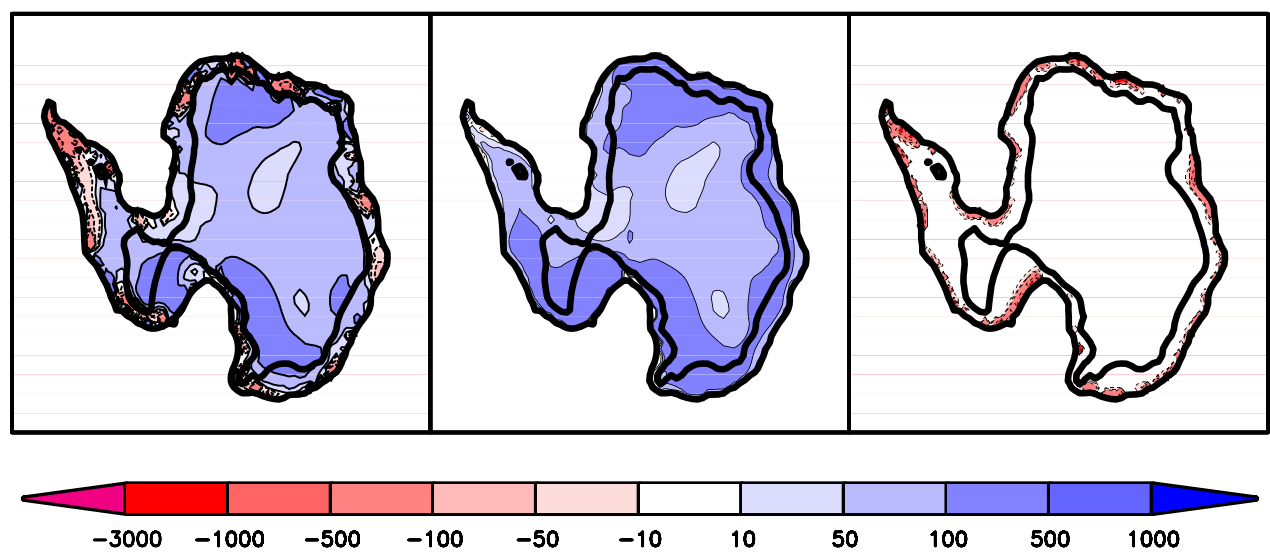

the AIS in all the greenhouse simulations, except for some small areas at the margin of the ice sheets, at topographic heights lower than $2,000 \mathrm{~m}$. Changes in the mass balance are dominated by changes in accumulation (Fig. 10). Snowfall anomalies are positive in all zones of Antarctica, due to increase in precipitation at high latitudes in the model except in some areas of the North Atlantic under the influence of a weakened/collapsed NAMOC, and to the low temperatures not enabling an increase of the fraction of precipitation falling as rain. This increase of precipitation in Antarctica is in agreement with the results of the models from the IPCC AR4 (Meehl et al. 2007), which show precipitation increase at high latitudes as a consequence of a general intensification of the global hydrological cycle, which is consistent with the higher moisture carrying capacity of warmer air.

The surface melting increases only in the Antarctic Peninsula and in some of the low elevated marginal areas of the ice sheet. Changes in the horizontal transport of ice are responsible for minor differences between local surface mass balance and total (vertically integrated) mass balance. No significant changes in the horizontal transport occur for the high elevation areas of the East Antarctic Plateau.

The contribution to the mass balance of changes in the ice dynamics at the margin of the ice sheet cannot be evaluated with our ISM. Ice shelves, ice streams, and outlet glaciers are not included. Therefore the above analysis lacks important components of the mass balance, which could be dominant over the next centuries. More details about the limitations of our analysis are given in Sect. 6.

\subsection{Sea level changes}

The increased storage of water in the AIS either compensates or exceeds the contribution to eustatic sea level rise from the GrIS. By year 1000, the contribution from the ice sheets to sea level changes is close to zero in the simulation $3 \times$, while it is a net lowering of the sea level in $2 \times$ and $4 \times$ (Fig. 5a, b). The contribution to sea level by year 1000 from oceanic thermal expansion (Fig. 5c) is $0.6 \mathrm{~m}(2 \times)$, $1.25 \mathrm{~m}(3 \times)$ and $1.5 \mathrm{~m}(4 \times)$. The maximum rate of thermal expansion occurs by year 300 in the case of $4 \times$, and is lower afterwards. The expansion has not reached an equilibrium by the end of the simulations. Maximum net sea level rise $(+1.1 \mathrm{~m}$, Fig. $5 \mathrm{~d})$ takes place at year 1000 in $3 \times$, and year 600 in $4 \times(+0.9 \mathrm{~m})$. This is due to the approximately linear increase of AIS volume with time, while the thermal expansion term slowly approaches an equilibrium value, and to the low contribution of GrIS to sea level rise in comparison with $3 \times$.

By the end of the simulations, the net sea level rise is largest in $3 \times(+1.1 \mathrm{~m})$ compared to $4 \times(+60 \mathrm{~cm})$ and $2 \times$ 
$(+20 \mathrm{~cm})$. The 2D pattern of sea level changes averaged for the period 900-1000 (Fig. 11) shows the lowest sea level rise (or a lowering of the sea level for $2 \times$ ) around Antarctica, due to the poleward shift of the location of convection. Maximum sea level rise occurs in the North Atlantic and in the Arctic in $4 \times$, due to the collapse of deepwater formation and stable stratification. The highest sea level rise $(+1.5 \mathrm{~m})$ is seen in Labrador Sea. Low sea level rise of only some tens of centimeter occurs in the northwest Pacific, due to enhanced formation of North
Pacific Intermediate Water. Mik07 give details of ocean circulation changes in this zone in the case of collapse of the NAMOC in several simulations forced with SRES scenario emissions. The patterns of sea level changes are similar for $2 \times$ and $3 \times$, since the ocean circulation is similar in both simulations. It must be noted that the calculations shown here do not include the effect of redistributions of sea level due to the changes in the gravitational attraction exerted by ice masses on the ocean waters (Mitrovica et al. 2001).
Fig. 11 Two-dimensional pattern of changes of sea level (m) due to ocean thermal expansion and changes in the volume of ice sheets for the simulations a $2 \times, \mathbf{b} 3 \times$, and c $4 \times$
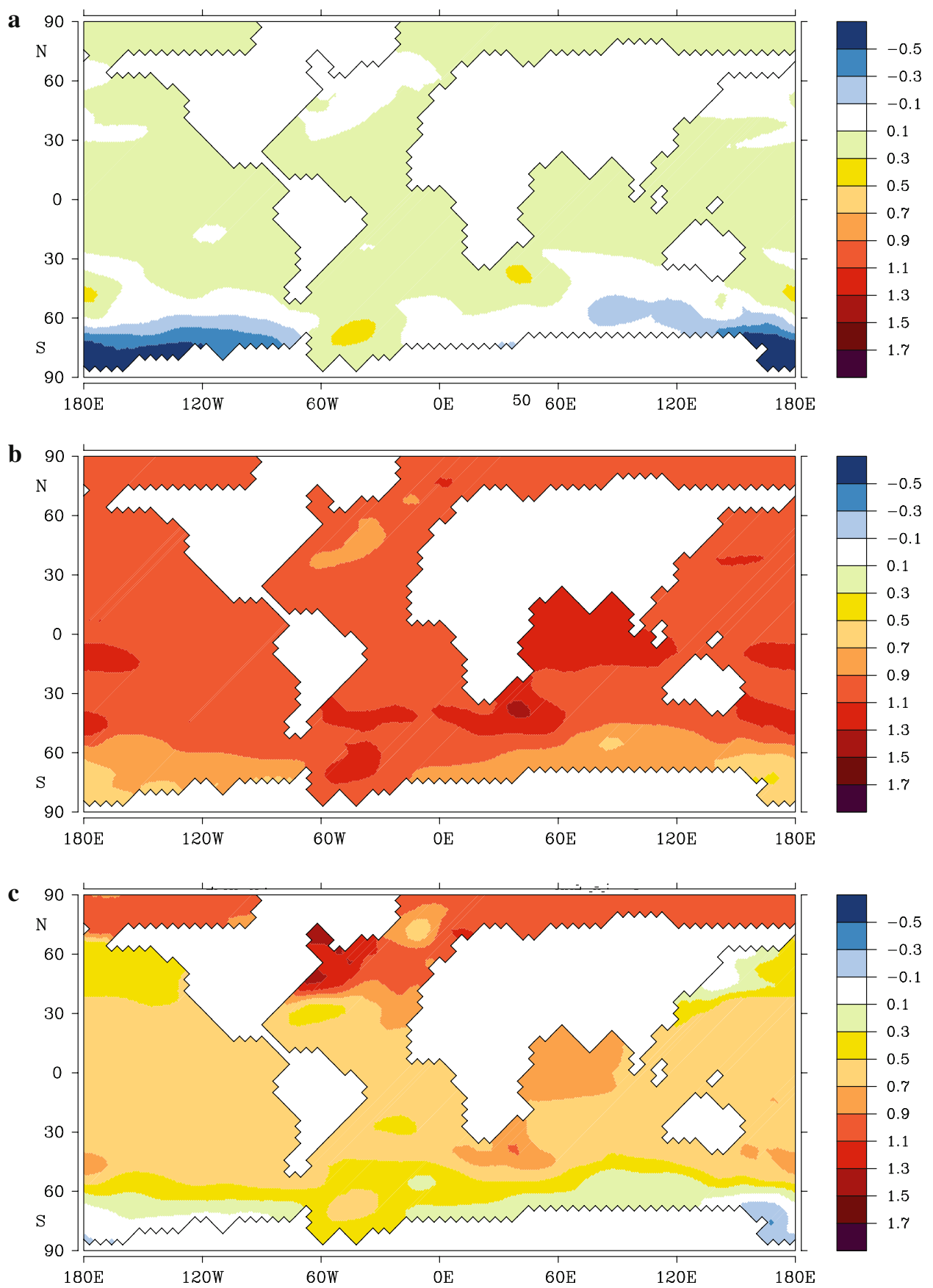


\section{Feedbacks between ice sheets and climate}

\subsection{Feedbacks between ice sheets and ocean circulation}

The reduction in the strength of the NAMOC in all the stabilisation simulations is related to increased stratification, caused by positive freshwater flux anomalies into the North Atlantic and Arctic and surface warming. These positive freshwater flux anomalies reach values as high as $0.2 \mathrm{~Sv}$ in $4 \times$ (Fig. 12a). The comparison of total net freshwater flux anomalies into the Arctic and North Atlantic basins between $2 \times, 3 \times$ and $4 \times$ and the corresponding simulations *_1w not including the feedbacks between ice sheets and climate is shown in Fig. 12a. Apart from in $4 \times$, the total net freshwater fluxes anomalies in the simulations including the extra meltwater from the ice sheets are not significantly higher than in the simulations *_1w. In $4 \times$, the total net freshwater flux anomaly into the North Atlantic basin at the time of the collapse of the NAMOC is approximately $0.1 \mathrm{~Sv}$. The contribution to this from the northern hemisphere ice sheets is less than $0.005 \mathrm{~Sv}$ (Fig. 12). From year 400, the freshwater flux from the ice sheets is less than $0.02 \mathrm{~Sv}$. Therefore, in $4 \times$, the relative contribution of the ice sheets to the net freshwater input into the North Atlantic/Arctic is always less than $10 \%$ of the total anomaly.

There are no substantial differences in the strength of the NAMOC between the simulations including the extra meltwater from the ice sheets and the simulations with meltwater fluxes as in CTRL (Fig. 2b). Thus the GrIS does
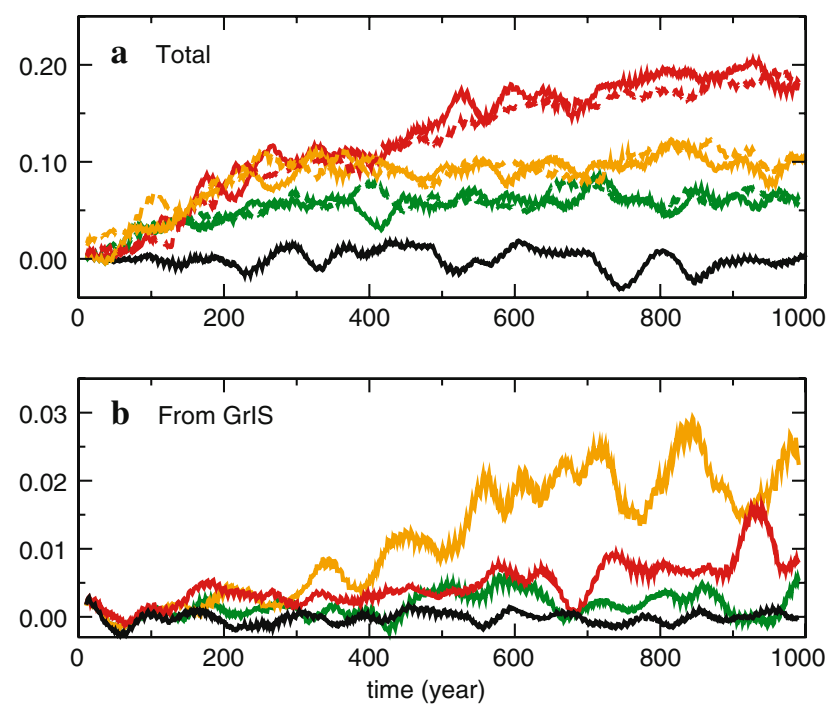

Fig. 12 a Total net freshwater flux anomalies into the North Atlantic and Arctic relative to CTRL mean (Sv) and $\mathbf{b}$ net freshwater fluxes (Sv) from the northern hemisphere ice sheets for $2 \times$ (green), $3 \times$ (yellow), $4 \times($ red $)$, CTRL (black), and the corresponding *_1w simulations (dashed). The time series are 20-year running means not play a major role in simulated stratification changes. Instead, increased atmospheric moisture transport into the North Atlantic drainage basin as well as ocean surface warming cause the weakening of the NAMOC.

The mass balance of the GrIS in these stabilisation scenario simulations has been shown to be highly sensitive to the climatic effects of changes in the NAMOC, the main effect being a drastic reduction of melting rates when significant weakening of the NAMOC occurs. This effect was shown to be particularly strong in the case of a complete collapse of Atlantic overturning: the contribution to sea level changes from the GrIS in $4 \times$, where the overturning collapses, is much lower than in $3 \times$, where the overturning weakens but recovers afterwards. Thus, in $4 \times$, the regional climate signal associated with a collapse of the NAMOC is dominant over the stronger global warming signal associated with higher $\mathrm{CO}_{2}$ forcing and the collapse of NADW formation leads to reduced melting especially over the southern half of the GrIS.

\subsection{Feedbacks between ice sheets and atmosphere}

Changes in the area and volume of the GrIS can affect the atmosphere by three main mechanisms: thermodynamic near-surface heating/cooling due to change of topographic height (discussed in Sect. 4.1.1), modification of the general circulation of the atmosphere caused by topographic and thermal contrast change, and changes of surface albedo due to changes in ice sheet area and presence of surface meltwater.

Comparison of $2 \times, 3 \times$ and $4 \times$ with the respective simulations *_1w shows no differences in the global mean temperature (Fig. 2a). Thus the ice sheet-atmosphere feedbacks do not have a global impact on the simulated climate.

The evolution of the integral volume of the GrIS in the simulations where the feedbacks are suppressed shows no significant differences from the simulations where the feedbacks are included (Fig. 5a). The comparison of the $2 \mathrm{D}$ distribution of thickness changes over the ice sheet by the end of the simulation shows no significant differences either (not shown). Thus the feedbacks between the GrIS and the regional climate of Greenland are not playing a major role in the evolution of the GrIS itself in these simulations. Since the maximum decay of the GrIS in these stabilisation scenario simulations represents only $1 / 7$ of the original volume, it could be that at a later stage in the decay of the ice sheet the feedbacks between ice sheet and atmosphere become more relevant. In order to investigate this possibility, two multi-millennia simulations A2 and A2_1w are analysed, where carbon emissions have been prescribed as described in Sect. 3.1. The modelled 

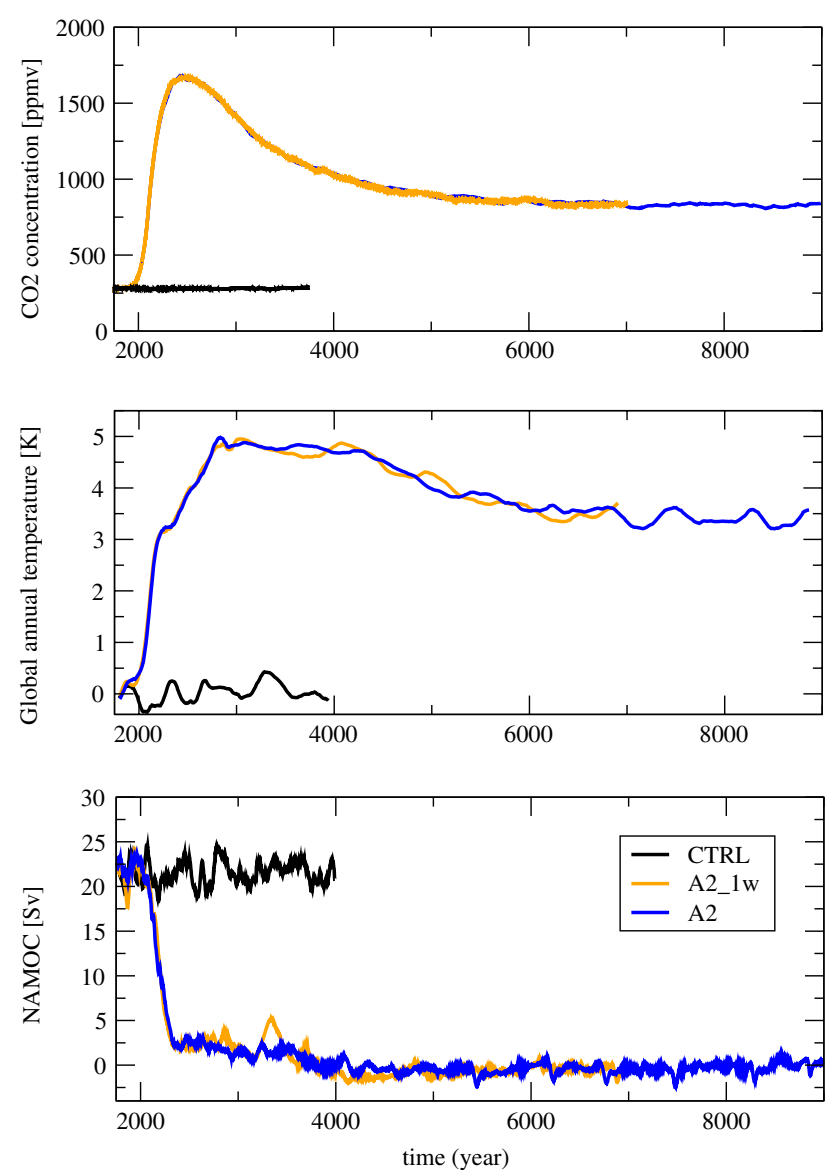

Fig. 13 a Atmospheric $\mathrm{CO}_{2}$ concentration (ppmv), b global mean annual near-surface air temperature $(\mathrm{K})$ anomalies from CTRL mean, and $\mathbf{c}$ strength of the NAMOC (Sv) at $40^{\circ} \mathrm{N}$ and $1,500 \mathrm{~m}$ depth for the simulations A2 (blue), A2_1w (orange), and CTRL (black)

atmospheric concentration of $\mathrm{CO}_{2}$ for $\mathrm{A} 2$ peaks at year 2500 (1680 ppmv, Fig. 13a), whereas the prescribed emissions peak in the year 2100 with almost $29 \mathrm{GtC}_{\text {year }}{ }^{-1}$ and have been reduced at year 2500 by more than one order of magnitude to less than $2 \mathrm{GtC}$ year $^{-1}$. Whereas initially large fractions of the emitted carbon are absorbed by land vegetation and ocean, the terrestrial biosphere is soon saturated and acts in later phases of the experiment, when the atmospheric concentration of $\mathrm{CO}_{2}$ is going down, as a weak source. The slow transport of carbon to the deep ocean and the dissolution of calcium carbonate from the marine sediment are responsible for the slowly sinking atmospheric $\mathrm{CO}_{2}$ concentrations. The evolution of the global mean temperature is similar in A2 and A2_1w (Fig. 13b). Maximal warming occurs around year 3000, when the global annual mean is about $5 \mathrm{~K}$ higher than in CTRL. During the period $4000-6000$ it decreases by $1.5 \mathrm{~K}$, and afterwards remains stable until the end of the simulations. A2_1w was stopped at year 7000 , since the modelled climate is very close to steady state. From year 7000, the ISM was forced with the climate from the period 6000-7000. The NAMOC

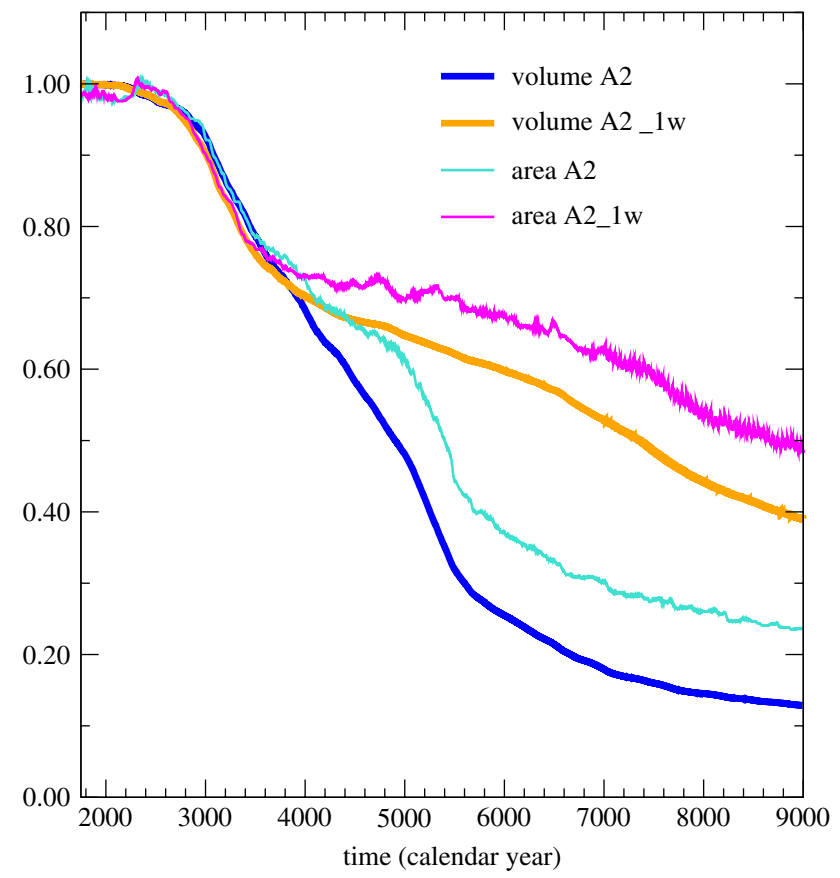

Fig. 14 Comparison of the GrIS volume and area changes expressed as percentage of the initial ones for the simulations A2 (volume blue, area turquoise) and A2_1w (volume orange, area magenta)

evolves similarly in A2 and A2_1w (Fig. 13c). It collapses between 2200 and 2300 and does not recover by the end of the simulations.

The volume and area of the GrIS (Fig. 14) evolve similarly in A2 and A2_1w until year 3600. From this time onwards, the rate of decay of the ice sheet diminishes significantly in A2_1w, while it remains unchanged in A2.

In $\mathrm{A} 2$, a period with strong melting rates occurs between the years 5000 and 5500. During this time, several points of the ice sheet deglaciate on the atmospheric grid. The marginal points of the ice sheet model close to those atmospheric grid points experience increased melting rates due to the warming associated with the changes in surface albedo. By 5500, the area of the ice sheet is reduced to $1 / 2$ of the original area. Most of the northern half of Greenland is icefree, except the central-east margin, where the bedrock is highest. By 7000 , the ice sheet is reduced to $1 / 5$ of its original volume. The small ice sheet is located at the southern tip and on the southeast coast. There the summer temperatures are lower than in the control simulation, due to the regional climate change associated with a collapsed NAMOC. The topography of the ice sheet at the southern tip of Greenland has remained almost unchanged since the beginning of the simulation, with its dome being always higher than $2,500 \mathrm{~m}$. In A2_1w, the area has fallen to only $62 \%$ of the initial extent and the volume to $52 \%$ by year 7000 .

Although the evolution of global mean temperature is similar in A2 and A2_1w, the regional climate over 

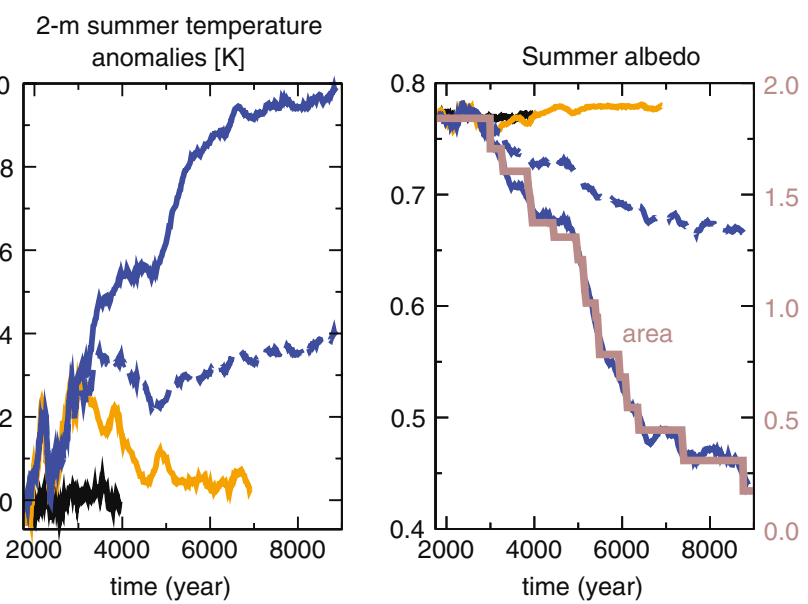

Fig. 15 a Evolution of anomalies with respect to the CTRL mean of summer near-surface temperature $(\mathrm{K})$ integrated over the area of the CTRL GrIS: CTRL (black), A2 (blue), A2 corrected at reference height of CTRL with an atmospheric lapse rate of $-6.5 \mathrm{~K} \mathrm{~km}^{-1}$ (dashed blue), and A2_1w (orange). b Averaged summer albedo of the reference GrIS area (blue A2, orange A2_1w), evolution of GrIS area in the atmospheric grid in A2 (maroon line) $\left(10^{6} \mathrm{~km}^{2}\right)$, and changes in the mean summer albedo of glaciated points of A2 (dashed blue line)

Greenland is strongly modified by changes in the GrIS. Until year 3200, the mean summer near-surface temperature averaged over the initial GrIS area is similar in A2 and A2_1w (Fig. 15a). After 3200, it is higher in A2. By the end of the simulation, the difference is approximately $10 \mathrm{~K} .60 \%$ of this anomaly can be explained by the heighteffect assuming a lapse rate of $-6.5 \mathrm{~K} \mathrm{~km}^{-1} ; 74 \%$ if a lapse rate of $-8 \mathrm{~K} \mathrm{~km}^{-1}$ is assumed. The rest of the signal must be explained by atmospheric circulation and albedo changes. The disappearance of the GrIS decreases the mean albedo by approximately 0.34 (Fig. 15b). The computation of the albedo of snow and ice on land surfaces in the AGCM depends on the surface type, the surface temperature and the fractional forest area. The albedo of land ice (glaciated areas) is substantially higher than the albedo of snow on ice-free land. The dependence of snow and ice albedo on surface temperature accounts for the presence of sub-grid areas reaching melting conditions when the averaged temperature of the grid AOGCM cell is close to melting point. Over melting surfaces the albedo decreases drastically due to the presence of water. The albedo decrease during the simulation A2 is due to two phenomena: the decrease of the glaciated area and the increase of surface temperatures. The evolution of the mean albedo is mainly controlled by the changes in the glacier mask (Fig. 15a). An albedo reduction of 0.15 in the ice-covered area results from changes in surface temperature (dashed blue line in Fig. 15b).

The almost complete disappearance of the GrIS by the end of A2 strongly modifies the climate of Greenland, and less strongly the climate of other areas in the northern hemisphere. During winter (Fig. 16a), the near-surface temperature in the interior of Greenland increases by $7 \mathrm{~K}$. The positive anomaly extends eastwards of Greenland over the ocean at $70-80^{\circ} \mathrm{N}$. Over Hudson Bay and northern Eurasia, temperatures decrease, with maximal decrease over Central Siberia. During summer (Fig. 16b) the largest climatic changes take place in Greenland, where the warming is of $10 \mathrm{~K}$ on average and reaches up to $12 \mathrm{~K}$ in the interior. The far-field response is similar to the winter response, although weakened. The absence of the GrIS in the $4 \times \mathrm{CO}_{2}$ simulation from Ridley et al. (2005) produces a local warming in Greenland of $7.8 \mathrm{~K}$ in winter and
Fig. 16 Differences in nearsurface temperature $(\mathrm{K})$ between A2 and A2_1w during winter (December-JanuaryFebruary upper panel) and summer (June-July-August lower panel) for the period 8000-9000. The green line delimits the areas where the anomalies are statistically significant
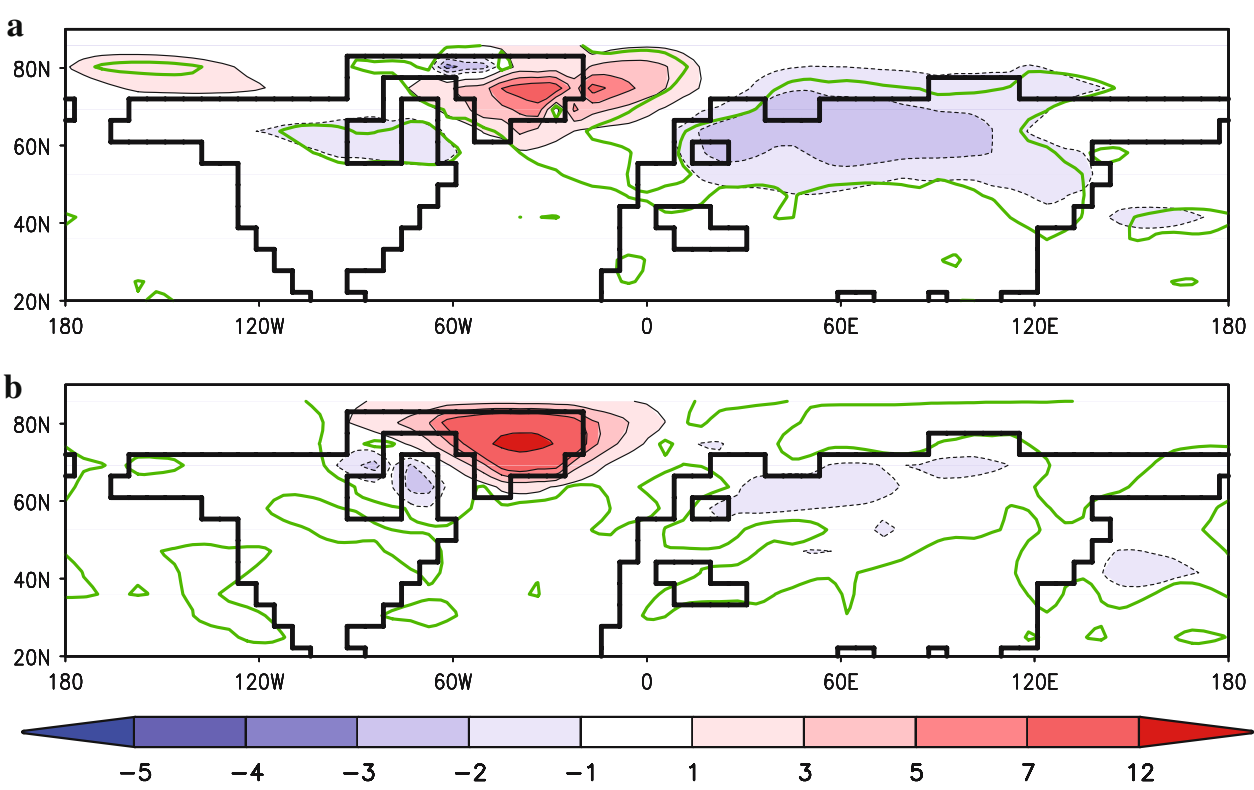
13.1 $\mathrm{K}$ in summer. The most important far-field change is a cooling over Scandinavia. This feature also appears in the results from Toniazzo et al. (2004), Lunt et al. (2004), and Junge et al. (2005), where the GrIS is removed from a preindustrial or present-day climate. In order to study the atmospheric impact of Greenland deglaciation in a preindustrial climate, which would be directly comparable to these previous studies, we will analyse in the following the simulation CTRL_NOGr. The setup of CTRL_NOGr is identical to CTRL, except for the initial GrIS, which is taken from its configuration in A2 by year 9000, when only a small ice sheet remains at the southern tip of Greenland. This simulation shows a maximal decrease of near-surface temperature in Scandinavia and the Baltic Sea instead of Central Siberia (not shown), as in the previously cited literature. Therefore, in our model, the far-field response of the atmosphere to the absence of the GrIS shows differences in the human-perturbed climate of A2 and in the preindustrial climate, unlike in the studies of Ridley et al. (2005) and Toniazzo et al. (2004), both performed with the same AOGCM.

Changes in the heat flux export integrated over the entire atmospheric column show an opposite pattern over Greenland for the winter and summer seasons (Fig. 17). During winter, the atmosphere over Greenland imports more heat from other regions when the ice sheet is removed. During summer, the anomalies of heat divergence over Greenland are positive. Warm air is exported from the Greenland area, warmer due to albedo reduction, to neighbouring regions. This explains the warming in the surroundings of Greenland (Fig. 16). During winter, the atmosphere over the North Atlantic imports less heat in the simulation without the GrIS, with maximum changes at $70^{\circ} \mathrm{N}$.
Figures 18 and 19 show the changes in the mean and transient atmospheric circulation during boreal winter due to the absence of the GrIS at the end of the simulation A2. We focus on winter changes (December-January-February) because circulation changes are strongest at that time of the year. When compared with CTRL (not shown), the mean circulation of A2_1w (Fig. 18a) over the North Atlantic is more zonal. The absence of the GrIS extends the climatological ridge east of Greenland into the North Atlantic north of $50^{\circ} \mathrm{N}$, Scandinavia and Greenland itself (Fig. 18b). Due to the absence of the GrIS, the storm track strengthens over most of Greenland and weakens over the Norwegian, North and Baltic Seas and over Scandinavia, central Europe, northern Eurasia and northern Canada (Fig. 19). The calculation of the storm track follows the method in Blackmon (1976). The storm track shifts southward over the North Pacific. These changes can be summarised in a southward shift of the storm track in the northern hemisphere and an increase over Greenland. The increase over Greenland explains part of the observed local near-surface warming, and the decrease over northern Eurasia, part of the cooling in this region. It should be noted that the resolution of the atmospheric model, T21, might be too low for a realistic simulation of storm tracks (Kageyama et al. 1999).

\subsubsection{Irreversibiliy of the deglaciation of Greenland}

In order to address the question of whether the GrIS would regrow if $\mathrm{CO}_{2}$ atmospheric concentration returned to preindustrial levels, the evolution of the simulation CTRL_NOGr is analysed in the following. This simulation
Fig. 17 Heat divergence anomalies $\left(\mathrm{Wm}^{-2}\right) \mathrm{A} 2-\mathrm{A} 2 \_1 \mathrm{w}$ for winter (upper panel) and summer (lower panel) by the end of the simulation (average period 8000-9000)
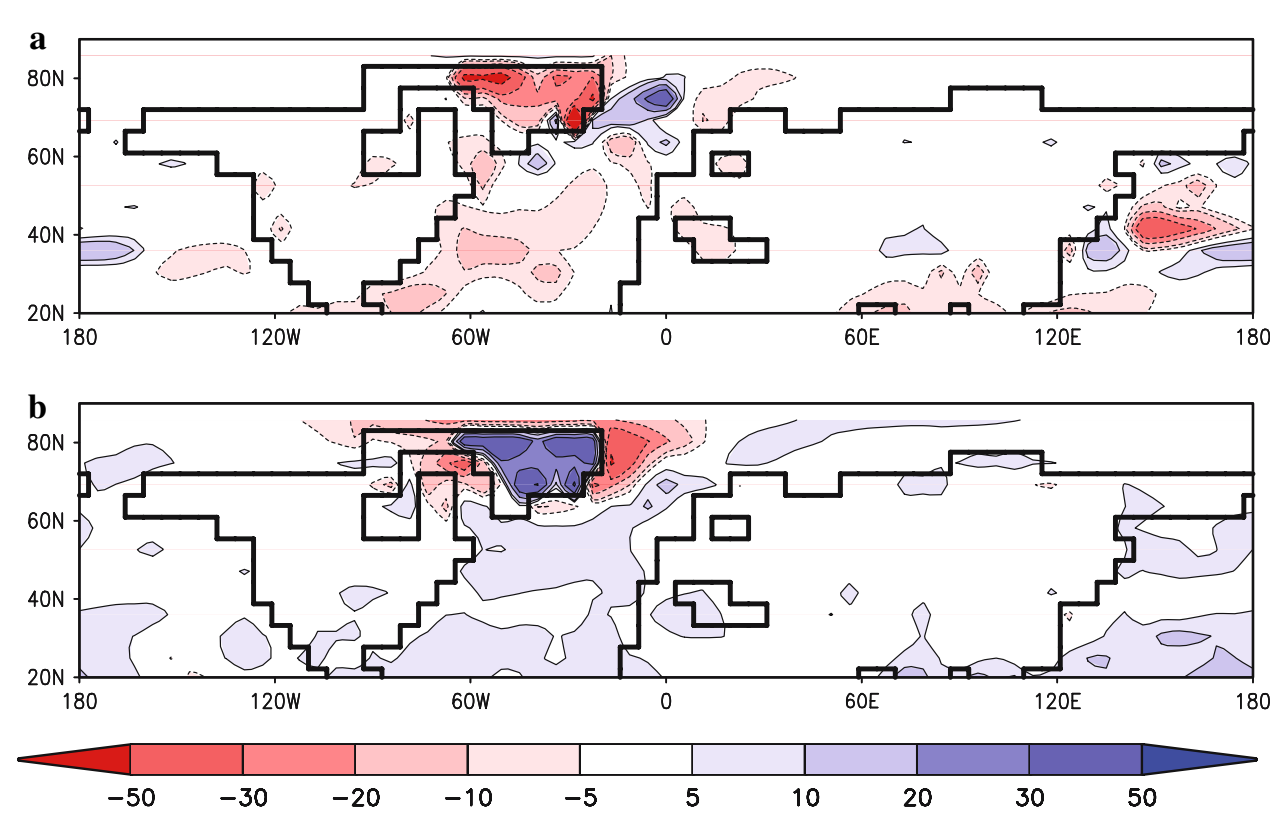

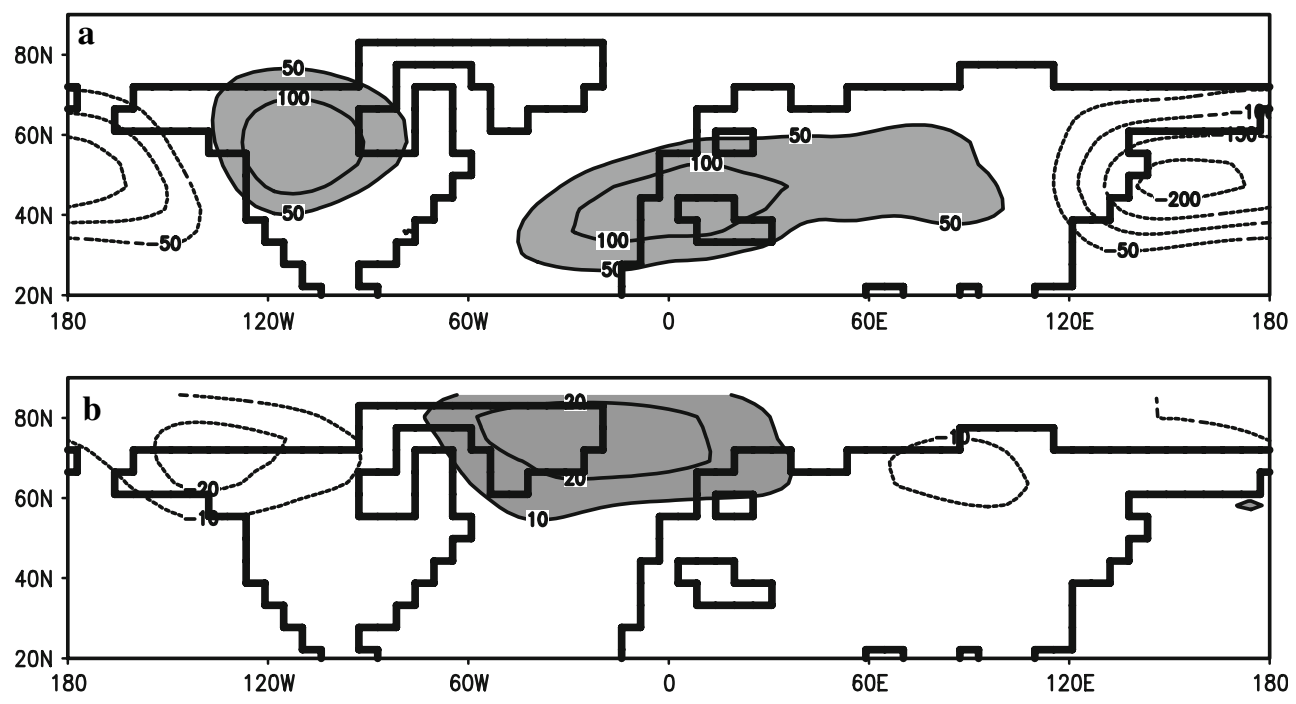

Fig. 18 Winter geopotential height anomalies to the zonal mean (gpm) at $500 \mathrm{hPa}$ for the period 8000-9000: a from A2_1w; b differences between A2 and A2_1w

has a length of 1,000 years. The small initial GrIS taken from the end of A2 does not expand (Fig. 20), and even slightly decays due to the absence of the regional cooling signal associated with a collapsed NAMOC, which was present in A2. Therefore the climate change associated with the absence of the GrIS from a climate with preindustrial boundary conditions is strong enough to prevent the glaciation of Greenland, due to the contributions from increased albedo, reduced topographic height and changes in the atmospheric circulation. According to this result, the GrIS is bi-stable under pre-industrial conditions of insolation and $\mathrm{CO}_{2}$, since the climate system maintains two equilibrium states depending on the initial boundary conditions: a glaciated state with a pre-existing ice sheet, and a non-glaciated Greenland, if Greenland is initially ice-free. Other studies dealing with this question found diverse answers. Crowley and Baum (1995) and Toniazzo et al. (2004) found that the ice sheet is bi-stable, not being able to grow if the initial state is an ice-free Greenland. Calov et al. (2005) also found two equilibrium states, a glaciated and a non-glaciated Greenland, in equilibrium simulations performed with the EMIC CLIMBER-2. On the contrary, the GrIS regrows from an initial non-glaciated state in Lunt et al. (2004) (Fig. 20).

\section{Summary and conclusions}

This study is one of the first investigating the interactions of ice sheets and climate with a coupled Earth System Model (ESM) consisting of General Circulation Models (GCMs). Our approach permits us to address the long-term effects of freshwater fluxes on ocean circulation and ice sheet topography and albedo changes on the atmosphere.
Also, we can evaluate whether these changes in the climate system driven by the ice sheets are important for ice sheet mass balance and therefore whether these feedbacks should be taken into account in studies of ice sheet evolution.

Our results show a relatively small loss of mass from the GrIS compared with other studies. For instance, Alley et al. (2005) obtained sea level rises of 1, 2, and $3 \mathrm{~m}$ after 1,000year simulations with the ice sheet model of Huybrechts and de Wolde (1999) forced with a uniform increase in mean annual temperature obtained from an average of seven IPCC models under scenarios where atmospheric $\mathrm{CO}_{2}$ stabilised at 550, 750 and 1,000 ppmv, respectively. Ridley et al. (2005) obtained an almost complete elimination of the GrIS within 3,000 years under constant $4 \times \mathrm{CO}_{2}$ forcing. After the first 1,000 years, the ice sheet decays to $40 \%$ of the initial volume. The smaller loss of mass by the GrIS in our study is due to the lower climate sensitivity of this ESM and to the regional effects over the GrIS of a weakened/collapsed NAMOC.

Since our meltwater fluxes from the GrIS are one order of magnitude smaller than atmospheric moisture transport anomalies, they do not play a major role in changes in the NAMOC. Huybrechts et al. (2002) coupled a 3D ice sheet model of the GrIS to the AOGCM LMD5.3-CLIO at a coarse resolution. The changes in the geometry of the GrIS were not passed, however, to the atmospheric component. They applied the SRES B2 scenario to this model and found a GrIS contribution of $4 \mathrm{~cm}$ to sea level rise by 2100 . About $0.03 \mathrm{~Sv}$ of additional freshwater fluxes enters the North Atlantic. They did not find significant changes in the patterns of climate change over the North Atlantic region compared with a climate-change run without Greenland freshwater feedback. Ridley et al. (2005) found a small effect of Greenland melting on the NAMOC. In their 
Fig. 19 The winter 500-hPa geopotential height 2.5-6 days bandpass statistics (gpm) for the period 8000-9000: a from A2_1w; b differences between $\mathrm{A} 2$ and $\mathrm{A} 2$ - $1 \mathrm{w}$
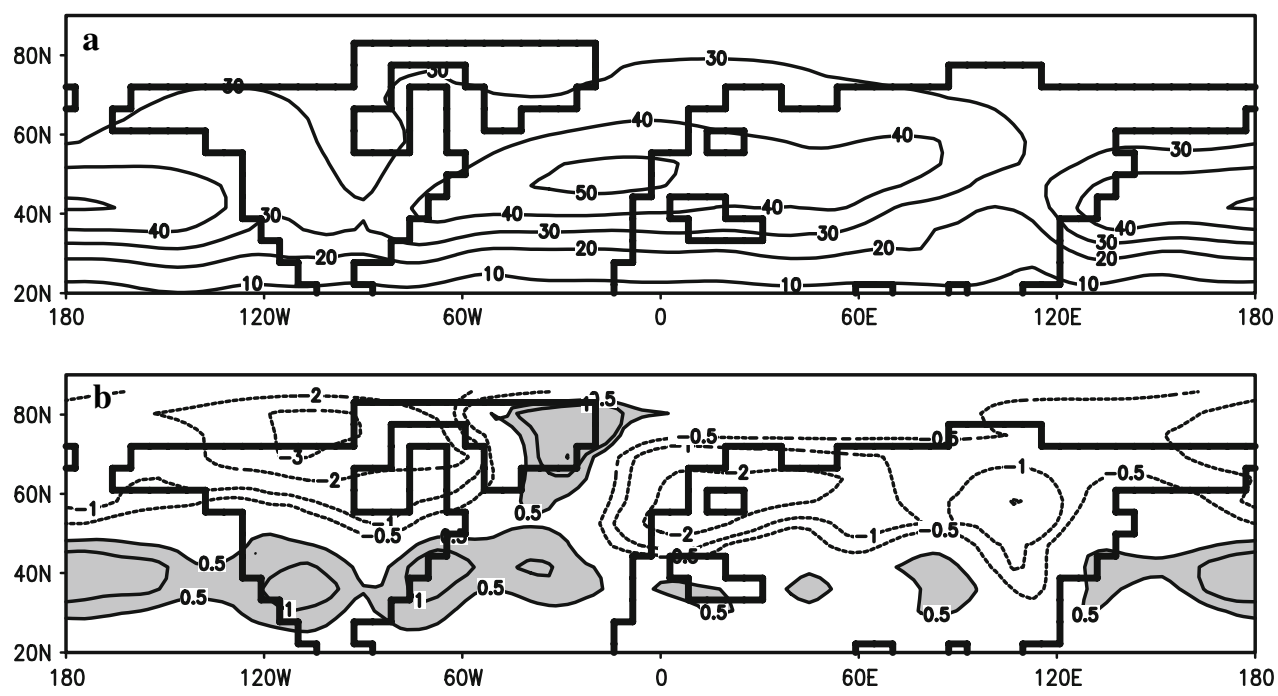

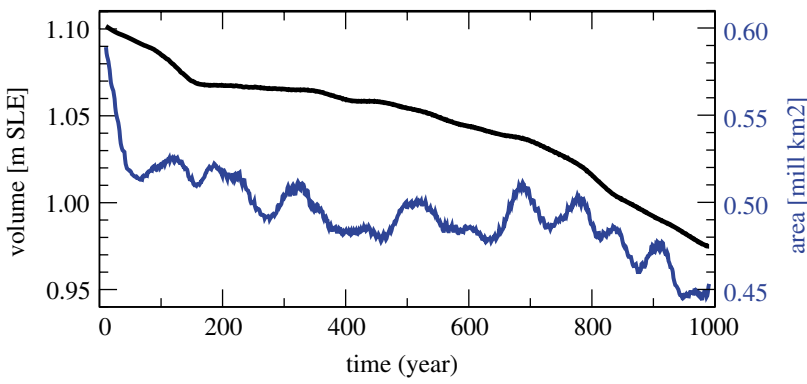

Fig. 20 Northern hemisphere ice sheet volume (black) and area (blue) evolution in CTRL_NOGr. The $x$-axis corresponds to time (model years)

model, the freshwater fluxes from Greenland peak at 0.06 Sv, causing an additional 1-2 Sv decrease in the strength of the overturning. By contrast, Fichefet et al. (2003) report a strong influence of the GrIS meltwater discharge on the NAMOC until the year 2100 , although the simulated freshwater fluxes $(0.015 \mathrm{~Sv})$ are comparable to the results of this study. However, their control simulation showed a considerable drift towards a weaker NAMOC. Therefore their results could be affected by model drift or their model could be close to a bifurcation point of the NAMOC, at which even very small perturbations could have a strong effect. In Driesschaert et al. (2007) the freshwater flow from the melting GrIS remains above $0.1 \mathrm{~Sv}$ for 3 centuries for the most extreme forcing scenario selected for their study, but only a slight decline of the NAMOC is simulated. Swingedouw et al. (2006) also report a strong contribution of ice sheet melting to the reduction of the NAMOC in their simulations, where the $\mathrm{pCO}_{2}$ concentration is prescribed to increase by $1 \%$ per year. Ice sheet melting increases from 0 to $0.2 \mathrm{~Sv}$ from year 0 to year 140 . In the $2 \times \mathrm{CO}_{2}$ simulation of Swingedouw et al. (2007), the contribution of ice sheet melting brings the NAMOC to a collapse. In the study of Mikolajewicz et al. (2007b), the effect from meltwater fluxes from ice sheets is negligible in the phase of initial weakening of the NAMOC, but turns to be more important during the recovery in subsequent centuries. In their $2 \times \mathrm{CO}_{2}$ simulation, ice sheet melting contributes by $0.025-0.03 \mathrm{~Sv}$ to total freshwater anomalies, and hinders the recovery of the NAMOC.

Here, changes in the mass balance of the GrIS have been shown to be highly influenced by regional climate change associated with a weakened NAMOC. A substantial reduction of melting rates accompanies the collapse of the NAMOC in a simulation where the greenhouse gas concentrations have been set to four times pre-industrial levels. The contribution of the GrIS to sea level changes is much lower than the contribution of the ice sheet in a simulation with three times pre-industrial levels. The reduction of melting rates over the GrIS as a consequence of regional climate changes caused by a weakening of the NAMOC could act as a stabilising mechanism for the strength of the overturning in the case of a dominant role for freshwater fluxes from the GrIS in weakening the NAMOC, as it reduces the freshwater input into the North Atlantic and this favouring again stronger NADW formation. However, this is not the only mechanism at work and in our model the changes in atmospheric moisture transports dominate over this ice sheet feedback.

In common with Huybrechts and de Wolde (1999) and Huybrechts et al. (2002), changes in ice sheet dynamics are found to act as a mechanism accelerating the decay of the GrIS. Changes in the horizontal transport caused by changes in the topography, however, act to reduce the integrated surface melting in the first stages of decay of the ice sheet, until the increased transport lowers a sufficient area in the interior of the ice sheet to a height with warmer surface temperatures permitting summer surface melting. 
According to our results, the positive atmospheric feedbacks associated with the decay of the GrIS are not relevant for the mass balance of the ice sheet until sufficient changes in the topography and area of the ice sheet have taken place. This threshold was found to be at $3 / 4$ of the original volume and area of the ice sheet. Accelerated GrIS decay is due to increased surface melting, and seems to be caused by enhanced warming due to a reduction in summer albedo. However, an additional simulation separating the albedo contribution to the total changes in the climate of Greenland from other effects would be needed to quantify more rigorously the role played by albedo. In Ridley et al. (2005), the threshold was found to be at $2 / 3$ of the original volume. They found that the processes associated with the decay of the ice sheet act as a negative feedback for its decay. This reduction of the decay rate takes place via the development of atmospheric convection due to the strong thermal contrast in their model between the deglaciated margins and the glaciated areas. They suggest that the development of these circulation cells may be a function of GCM resolution. These convective cells do not develop in our ESM, where the resolution is lower and where the thermal contrast between deglaciated and glaciated model points is substantially weaker than in the results of Ridley et al. (2005).

In our model, the GrIS cannot regrow after deglaciation if atmospheric $\mathrm{CO}_{2}$ levels would return to pre-industrial levels. Therefore, the GrIS is, according to our results and in agreement with Crowley and Baum (1995) and Calov et al. (2005), bi-stable.

Regarding the AIS, our results show a net gain of mass of the ice sheet for all the stabilisation scenarios. Church et al. (2001) predict a continuous growth of the AIS, which compensates enhanced melting rates from the GrIS, up to the year 2100. Simulations with the 3D ice sheet model of Huybrechts and de Wolde (1999) passively coupled to a 2D climate model show a moderate and constant lowering of sea level, reaching 30 and $50 \mathrm{~cm}$ by the (calendar) year 3000 for doubling and quadrupling of $\mathrm{CO}_{2}$ simulations, respectively. For the $8 \times \mathrm{CO}_{2}$ scenario, the contribution of the AIS to sea level rise is positive, due to increased surface melting in the margins and increased basal melting in the ice shelves caused by warmer ocean temperatures. Ice shelves are not properly modelled in the ice sheet model used in our study. Therefore a potential retreat of the grounding line in the West AIS caused by the thinning of ice shelves due to enhanced ocean heat fluxes cannot be simulated. Warner and Budd (1998) and Huybrechts and de Wolde (1999) showed that grounding line retreat along the ice shelves could happen for basal melting rates $>5$ $10 \mathrm{~m} \mathrm{year}^{-1}$, destroying the West Antarctic Ice Shelves after a few centuries. Recent measurements show an increase in bottom melting near the AIS grounding lines (Rignot and Jacobs 2002).

The main limitations of this study are associated with the use of the Shallow Ice Approximation (SIA), the coarse resolution of the ice sheet and atmospheric models, and the use of flux corrections at the interface atmosphere-ice sheet.

Most ice sheet models are based on the SIA (Hutter 1983), which is valid for an ice mass with a small aspect ratio (vertical dimension $\ll$ horizontal dimension). The SIA is not a good approximation at all places in the ice sheet, such as at the ice divide or near the ice margin (Baral et al. 2001). The dynamics of ice streams, outlet glaciers and ice shelves cannot be modelled with our ice sheet model. Recent measurements of acceleration of ice streams and outlet glaciers in Greenland (Rignot and Kanagaratnam 2006; Joughin et al. 2004) and Antarctica (Scambos et al. 2004; Shepherd et al. 2002; Joughin et al. 2003) reveal that rapid dynamic changes can be important, contributing a substantial fraction of the ongoing sea level rise and potentially becoming dominant over ice sheet mass balance changes in the future. Models including the full set of physical processes implicated in the ongoing changes are needed to assess if these ongoing changes represent minor perturbations before stabilisation or a major change affecting sea level substantially (Alley et al. 2005).

The resolution of the atmospheric model is critical for an accurate modelling of precipitation over the ice sheets (Ohmura et al. 1996). The lower the resolution, the higher the overestimation of precipitation due to reduced orographic forcing. Our relatively high growth rates for the AIS are influenced by overestimation of precipitation associated with the coarse resolution and by the use of absolute precipitation anomalies instead of rate anomalies in the flux correction, a choice taken for mass conservation purposes. Therefore our quantitative results for the AIS and its effect on sea level should be interpreted with caution. The effect of precipitation increase on the total mass balance of the GrIS is also probably overestimated due to the same reasons. Besides, higher resolution in the ice sheet model would resolve better the width of the ablation area (Wild et al. 2003), because the margins of ice sheets are very steep.

Another critical issue is certainly the use of anomalies rather than using directly the forcing data from the AGCM, which might distort bifurcation diagrams. First simulations from a new ESM indicate that it seems to be possible to obtain a reasonable ice sheet climate without flux correction if a higher resolution AOGCM with improved physical parameterisations in the atmospheric component is used (Vizcaíno 2006; Mikolajewicz et al. 2007b).

From our results we conclude that ice sheets are an active component of the climate system, with changes in their mass balance being able to modify substantially their 
own climate and the climate of other regions. Therefore we encourage their inclusion as dynamical components of climate models, in order to obtain more accurate projections of sea level changes and patterns of climate change, and in order to improve our understanding of the feedbacks operating between them and the rest of components of the climate system.

Acknowledgments This work was performed within the project CLIMCYC, funded by the DEKLIM program of the German Ministry of Education and Research. Arne Winguth is supported by NASA grant NAG5-11245 and the UW Graduate School Research Funds. The simulations have been performed at the "Deutsches Klimarechenzentrum". Prof. Ralf Greve is thanked for his support with the ice sheet model and Dr. Hugo Lambert for his advice on the grammar and style of the manuscript. Two anonymous reviewers are thanked for their constructive comments to the manuscript. Dr. Sven Kotlarski, Dr. Helmut Haak and Dr. Felix Landerer contributed with helpful remarks to the first version of the manuscript.

\section{Appendix : Comparison of our model results with standard model intercomparison projects}

In order to place the model results into perspective, we show here a short comparison with results from other models, as published in intercomparison projects. All but one of the simulations presented in this Appendix have been run without interactive ice sheets. As reference we use the long-term mean values of the control simulation. Our results differ from most other models used in the comparison as they include a dynamic vegetation component. Two types of sensitivities are investigated. The first is a simulation with a prescribed exponential increase in atmospheric $\mathrm{CO}_{2}$ concentration until $4 \times$ the pre-industrial concentration is reached after 140 years. The detailed setup as well as the results from the participating coupled climate models is presented in Gregory et al. (2005). We use the first 140 years of our $4 \times \_1 w$ and $4 \times$ experiments. Two more simulations corresponding to $4 \times \_1 \mathrm{w}$ but with different initial conditions and a synchronous version of $4 \times \_1 \mathrm{w}$ are used here as well. The mean reduction of the maximum of the NAMOC is (averaged over the 20 years prior to reaching the final $\mathrm{pCO}_{2}$ level) $7 \mathrm{~Sv}$ (individual values between 6 and $8 \mathrm{~Sv}$ ), which is equivalent to a $26 \%$ reduction. The reductions in the models analysed in Gregory et al. (2005) vary between 10 and 50\%. Relating the reduction to the strength of the mean overturning as is done in Fig. 3 of Gregory et al. (2005), our model shows a relative reduction in overturning compared to its mean strength which is slightly weaker than suggested by the mean regression line in this figure, which has a slope of $-0.45 \pm 0.14$ ( $y$ against $x$ ).

The second set of experiments investigated the stability against additional meltwater input of $0.1 \mathrm{~Sv}$ into the North
Atlantic for 100 years and a continuation of these simulations without further perturbation. Details of the experimental setup and the results of other models can be found in Stouffer et al. (2006). We performed an ensemble integration with three experiments with fully synchronous coupling. Averaged over the years $81-100$ the maximum of the meridional overturning stream function in the North Atlantic was reduced from 27 to $19 \mathrm{~Sv}$ on average. Individual realisations varied between 17 and $22 \mathrm{~Sv}$. This represents a reduction in the range of 5-10 Sv. The relative reduction of $30 \%$ is almost exactly the average of all the other models. The absolute reduction is larger than the average reduction of slightly more than $5 \mathrm{~Sv}$ in all the participating models, but the overturning in our model is also larger than the average from the other models. After switching off the meltwater perturbation all simulations recovered-with some temporary overshooting - to the control climate. The relative large spread within the (small) ensemble demonstrates the value of ensemble simulations.

The mean cooling associated with the weakening of the overturning over the years $81-100$ of the meltwater experiment is shown in Fig. 21. The center of the simulated cooling lies at the southeast coast of Greenland, where our model forms most of its North Atlantic deepwater. Magnitude and pattern are rather similar to the results from a couple of other coupled climate GCMs like, e.g., ECHAM5/MPI-OM, the two GFDL models and the CCC_GCM2. Other coupled GCMs showed rather different patterns (see Fig. 4 from Stouffer et al. 2006).

Summarising the results, our model shows a reduction of the NAMOC in response both to additional freshwater input as well as to increase in atmospheric $\mathrm{CO}_{2}$ concentration that is comparable to the results from other coupled climate models. The same is true for the near-surface air temperature response in response to meltwater input.

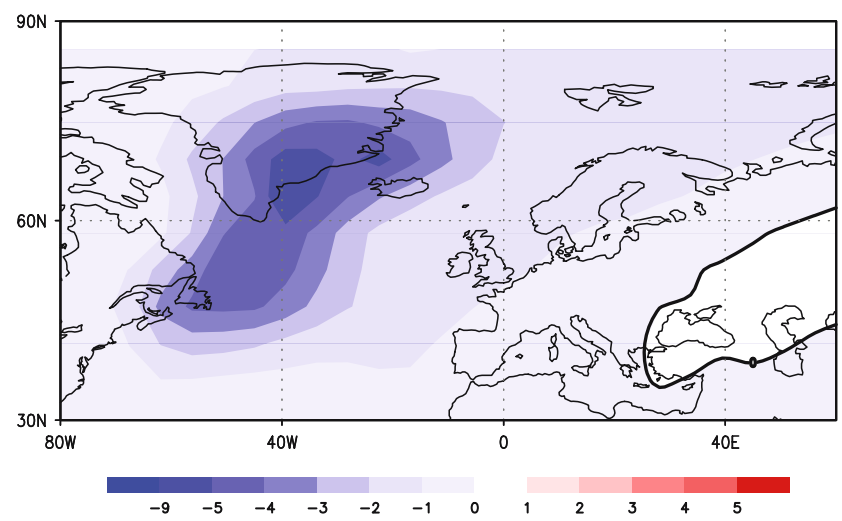

Fig. 21 Near-surface temperature anomalies in the North Atlantic region with respect to CTRL from a three-member ensemble simulation where $0.1 \mathrm{~Sv}$ of additional meltwater are delivered to the North Atlantic during years $0-100$, following Stouffer et al. (2006). The figure shows the average from years $81-100$ 


\section{References}

Alley RB, Clark PU, Huybrechts P, Joughin I (2005) Ice-sheet and sea-level changes. Science 310:456-460

Baral D, Hutter K, Greve R (2001) Asymptotic theories of large-scale motion, temperature, and moisture distribution in land-based polythermal ice sheets: a critical review and new developments. Appl Mech Rev 54:215-256

Blackmon M (1976) A climatological spectral study of the $500 \mathrm{mb}$ geopotential height of the northern hemisphere. J Atmos Sci 33:1607-1623

Braithwaite RJ, Olensen OB (1989) Calculation of glacier ablation from air temperature, West Greenland. In: Oerlemans J (ed) Glacier fluctuations and climatic change. Kluwer, Dordrecht, pp 219-233

Broecker WS, Andree M, Wolfli W, Oescher H, Bonani G, Kennet J, Peteet D (1988) The chronology of the last deglaciation: implications to the cause of the Younger Dryas event. Paleoceanogr 3:1-19

Budd WF, Smith IN (1979) The growth and retreat of ice sheets in response to orbital radiation changes. In: Sea level, ice, and climatic change, Proceedings of the Canberra symposium, IAHS Publ. 131

Bugnion V, Stone PH (2002) Snowpack model estimates of the mass balance of the Greenland ice sheet and its changes over the twentyfirst century. Clim Dyn 20:87-106

Calov R (1994) Das thermomechanische Verhalten des groenlaendischen Eisschildes unter der Wirkung verschiedener Klimaszenarien - Antworten eines theoretisch-numerischen Modells. Ph.D. thesis, stitut fuer Mechanik, Technische Hochschule Darmstadt, Germany

Calov R, Hutter K (1996) The thermomechanical response of the Greenland ice sheet to various climate scenarios. Clim Dyn $12: 243-260$

Calov R, Marsiat I (1998) Simulations of the northern hemisphere through the last glacial-interglacial cycle with a vertically integrated and a three-dimensional thermomechanical ice sheet model coupled to a climate model. Ann Glaciol 27:169-176

Calov R, Savvin AA, Greve R, Hansen I, Hutter K (1998) Simulation of the Antarctic ice sheet with a three-dimensional polythermal ice-sheet model, in support of the EPICA project. Ann Glaciol 27:201-206

Calov R, Ganopolski A, Claussen M, Petoukhov V, Greve R (2005) Transient simulation of the last glacial inception. Part I: Glacial inception as a bifurcation in the climate system. Clim Dyn 24:545-561

Church JA et al (2001) Changes in sea level. In: Houghton JT, Ding Y, Griggs DJ, Noguer M, Van Der Linden PJ, Dai X, Maskell K, Johnson CA (eds) Climate change 2001: the scientific basis. Cambridge University Press, Cambridge, pp 640-693

Crowley T, Baum S (1995) Is the Greenland ice sheet bistable. Paleoceanography 10:357-363

Cook K, Held I (1988) Stationary waves of the ice age climate. J Clim 1:807-819

Dansgaard WS, Johnsen S, Clausen H, Dahl-Jensen D, Gunestrup N, Hammer C, Hvidberg C, Steffensens J, Sveinbjörnsdottir A, Jouzel J, Bond G (1993) Evidence for general instability of past climate from a 250-kyr ice-core record. Nature 364:218220

ETOPO5 (1988) Data announcement 88-mgg-02, digital relief of the surface of the earth. Technical report, NOAA, National Geophysical Data Center, Boulder, Colorado, USA

Driesschaert E, Fichefet T, Goosse H, Huybrechts P, Janssens I, Mouchet A, Munhoven G, Brovkin V, Weber SL (2007) Modeling the influence of Greenland ice sheet melting on the Atlantic meridional overturning circulation during the next millennia. Geophys Res Lett 34(10):L10707. doi: 10.1029/2007GL029516,2007

Fichefet T, Poncin C, Goose H, Huybrechts P, Janssens I, Treut HL (2003) Implications of changes in freshwater flux from the Greenland ice sheet for the climate of the 21st century. Geophys Res Lett 30:1911

Gallee H, Ypersele JP, Fichefet T, Marsiat I, Tricot C, Berger A (1992) Simulation of the Last Glacial Cycle by a coupled, sectorially averaged climate-ice sheet model:2. Response to insolation and $\mathrm{CO}_{2}$ variations. J Geophys Res 97(D14):15,71315,740

Gent PR, Willebrand J, McDougall T, McWilliams JC (1995) Parameterizing eddy-induced tracer transports in ocean circulation models. J Phys Oceanogr 19:2962-2970

Gregory J, Huybrechts P, Raper S (2004) Threatened loss of the Greenland ice-sheet. Nature 428:616

Gregory JM, Dixon KW, Stouffer RJ, Weaver AJ, Driesschaert E, Eby M, Fichefet T, Hasumi H, Hu A, Jungclaus JH, Kamenkovich IV, Levermann A, Montoya M, Murakami S, Nawrath S, Oka A, Sokolov AP, Thorpe RB (2005) A model intercomparison of changes in the Atlantic thermohaline circulation in response to increasing atmospheric $\mathrm{CO}_{2}$ concentration. Geophys Res Lett L12703 32 (12):L12703. doi: 10.1029/2005GL0232091

Greve R (1995) Thermomechanisches Verhalten polythermer Eisschilde - Theorie, Analytik, Numerik. Ph.D. thesis, Institut fuer Mechanik, Technische Hochschule Darmstadt, Germany

Greve R (1997) Application of a polythermal three-dimensional ice sheet model to the Greenland ice sheet: response to steady-state and transient climate scenarios. J Clim 10:901-918

Greve R (2000a) On the response of the Greenland ice sheet to greenhouse climate change. Clim Change 46:289-303

Greve R (2000b) Paleoclimatic evolution and present conditions of the Greenland ice sheet in the vicinity of Summit: and approach by large-scale modelling. Paleoclimates 2:133-161

Greve R, Wyrwoll K, Eisenhauer A (1999) Deglaciation of the northern hemisphere at the onset of the Eemian and the Holocene. Ann Glaciol 28:1-8

Gröger M, Mikolajewicz U, Maier-Reimer E, Schurgers G, Vizcaíno M, Winguth A (2007) Changes in the hydrological cycle, ocean circulation and carbon/nutrient cycling during the last interglacial. Paleoceanography 22(4):PA4205

Holland MM, Bitz CM (2003) Polar amplification of climate change in coupled models. Clim Dyn 21:221-232

Houghton RA, Hackler JL (2002) Carbon flux to the atmosphere from land-use changes. In: Trends: a compendium of data on global change. Carbon Dioxide Information Analysis Center, Oak Ridge National Laboratory, U.S. Department of Energy, Oak Ridge, TN, USA

Houghton J, Ding Y, Griggs D, Noguer M, Van der Linden P, Dai X, Maskell K, Johnson CA (2001) Climate change 2001: the scientific basis. Cambridge University Press, Cambridge

Hutter K (1983) Theoretical glaciology. Kluwer, Norwell

Huybrechts P, de Wolde J (1999) The dynamic response of the Greenland and Antarctic ice sheets to multiple-century climatic warming. J Clim 12:2169-2188

Huybrechts P, Janssens I, Poncin C, Fichefet T (2002) The response of the Greenland ice sheet to climate changes in the 21 st century by interactive coupling of an AOGCM with a thermomechanical ice-sheet model. Ann Glaciol 35:409-415

Imbrie J, Martinson J, McIntyre D, Mix A, Morley J, Pisias N, Prell W, Shackleton N (1984) The orbital theory of Pleistocene climate: support from a revised chronology of the marine delta $0^{18}$ record. In: Berger A (ed) Milankovich and climate, part I, vol 126. D. Reidel Publishing Company, Dordrecht 
Joughin I, Rignot E, Rosanova CE, Lucchitta BK, Bohlander J (2003) Timing of recent accelerations of Pine Island Glacier, Antarctica. Geophys Res Lett 30(13):1706. doi:10.1029/2003GL017609

Joughin I, Abdalati W, Fahnestock M (2004) Large fluctuations in speed on Greenland's Jakobshavn Isbrae glacier. Nature 432:608-610

Jouzel J, Barkov NI, Barnola JM, Bender M, Chappelaz J, Genthon C, Kotlyakov VM, Lipenkov V, Lorius C, Petit JR, Raynaud D, Raisbeck G, Ritz C, Sowers T, Stievenard M, Yiou F, Yiou P (1993) Extending the Vostok ice-core record of paleoclimate to the penultimate glacial period. Nature 364:407-412

Jouzel J, Waelbroeck C, Malaize B, Bender M, Petit JR, Barkov NI, Barnola JM, King T, Kotlyakov VM, Lipenkov V, Lorius C, Raynaud D, Ritz C, Sowers T (1996) Climatic interpretation of the recently extended Vostok ice records. Clim Dyn 12:513-521

Junge MM, Blender R, Fraedrich K, Gayler V, Luksch U, Lunkheit F (2005) A world without Greenland: impacts on the northern hemisphere winter circulation in lowand high-resolution models. Clim Dyn 24:297-307

Kageyama M, Valdes PJ, Ramstein G, Hewitt C, Wyputta U (1999) Northern hemisphere storm tracks in present day and last glacial maximum climate simulations: a comparison of the European PMIP models. J Clim 12:742-760

Kageyama M, Charbit S, Ritz C, Khodri M, Ramstein G (2004) Quantifying ice-sheet feedbacks during the last glacial inception. Geophys Res Lett 31:L24203. doi:10.1029/2004GL021339

Le Meur E, Huybrechts P (1998) Present-day uplift patterns over Greenland from a coupled ice-sheet/visco-elastic bedrock model. Geophys Res Lett 25:3951-3954

Lunt D, de Noublet-Ducoudré N, Charbit S (2004) Effects of a melted Greenland ice sheet on climate, vegetation, and the cryosphere. Clim Dyn 23:679-694

Maier-Reimer E (1993) Geochemical cycles in an ocean general circulation model. Preindustrial tracer distributions. Global Biogeochem Cycles 7:645-677

Maier-Reimer E, Mikolajewicz U (1989) Experiments with an OGCM on the cause of the Younger Dryas. In: Oceanography 1988 (pp 87-100). UNAM Press, Mexico, 208 pp

Maier-Reimer E, Mikolajewicz U, Hasselmann K (1993) Mean circulation of the Hamburg LSG OGCM and its sensitivity to the thermohaline surface forcing. J Phys Oceanogr 23:731-757

Manabe S, Broccoli A (1985) The influence of continental ice sheets on the climate of an ice age. J Geophys Res 90:2167

Manabe S, Stouffer RJ (1988) Two stable equilibria of a coupled ocean-atmosphere model. J Clim 1:841-866

Manabe S, Stouffer RJ (1994) Multiple-century response of a coupled ocean-atmosphere model to an increase of atmospheric carbon dioxide. J Clim 7:5-23

Marland G, Boden T, Andres R (2005) Global, regional, and national fossil fuel $\mathrm{CO}_{2}$ emissions. In: Trends: a compendium of data on global change. Carbon Dioxide Information Analysis Center, Oak Ridge National Laboratory, US Department of Energy, Oak Ridge, TN, USA

Marsiat I (1994) Simulation of the northern hemisphere continental ice sheets over the last glacial-interglacial cycle: experiments with a latitude-longitude vertically integrated ice sheet model coupled to a zonally averaged climate model. Paleoclimates I:59-98

Masson-Delmotte V et al (2006) Past and future polar amplification of climate change: climate model intercomparisons and ice-core constraints. Clim Dyn 26:513-529

Meehl GA, Stocker TF, Collins WD, Friedlingstein P, Gaye AT, Gregory JM, Kitoh A, Knutti R, Murphy JM, Noda A, Raper SCB, Watterson IG, Weaver AJ, Zhao Z-C (2007) Global climate projections. In: Solomon S, Qin D, Manning M, Chen Z, Marquis M, Averyt KB, Tignor M, Miller HL (eds) Climate
Change 2007: the physical science basis. Contribution of Working Group I to the Fourth Assessment Report of the Intergovernmental Panel on Climate Change.Cambridge University Press, Cambridge

Mikolajewicz U, Gröger M, Maier-Reimer E, Schurgers G, Vizcaíno $\mathrm{M}$, Winguth A (2007a) Long-term effects of anthropogenic $\mathrm{CO}_{2}$ emissions simulated with a complex earth system model. Clim Dyn 28:599-633. doi:10.1007/s00382-006-0204-y

Mikolajewicz U, Maier-Reimer E (1994) Mixed boundary conditions in ocean general circulation models and their influence on the stability of the models conveyor-belt. J Geophys Res 99:2263322644

Mikolajewicz U, Vizcaíno M, Jungclaus J, Schurgers G (2007b) Effect of ice sheet interactions in anthropogenic climate change simulations. Geophys Res Lett 34:L18706. doi: 10.1029/2007GL031173

Mitrovica JX, Tamisiea ME, Davis JL, Milne GA (2001) Recent mass balance of polar ice sheets inferred from patterns of global sealevel change. Nature 409:1026-1029

Nakicenovic N, Alcamo J, Davis G, De Vries B, Fenhann J, Gaffin S, Gregory K, Grübler A, Jung TY, Kram T, Lebre La Rovere E, Michaelis L, Mori S, Morita T, Pepper W, Pitcher H, Price L, Riahi K, Roehrl A, Rogner H, Sankovski A, Schlesinger M, Shukla P, Smith S, Swart R, Van Rooijen S, Victor N, Dadi Z (2001) Special report on emissions scenarios. In: A special report of Working Group III of the Intergovernmental Panel on Climate Change. Cambridge University Press, Cambridge

Nakamura M, Stone PH, Marotzke J (1994) Destabilization of the thermohaline circulation by atmospheric eddy transports. J Clim $7: 1870-1882$

Ohmura A, Calanca P, Wild M, Anklin M (1996) A possible change in mass balance of Greenland and Antarctic ice sheets in the coming century. J Clim 9:2124-2135

Paterson W (1991) Why ice-age ice is sometimes "soft". Cold Reg Sci Technol 20:75-98

Petoukhov V, Claussen M, Berger A, Crucifix M, Eby M, Eliseev AV, Fichefet T, Ganopolski A, Goosse H, Kamenkovich I, Mokhov II, Montoya M, Mysak LA, Sokolov L, Stone P, Wang Z, Weaver AJ (2005) EMIC Intercomparison Project (EMIP): comparative analysis of EMIC simulations of climate, and of equilibrium and transient responses to atmospheric $\mathrm{CO}_{2}$ doubling. Clim Dyn 25:363-385

Rahmstorf S, Willebrand J (1995) The role of temperature feedback in stabilizing the thermohaline circulation. J Phys Oceanogr 25:787-805

Reeh N (1991) Parameterization of melt rate and surface temperature on the Greenland ice sheet. Polarforsch 59(3):113-228

Ridley JK, Huybrechts P, Gregory JM, Lowe JA (2005) Elimination of the Greenland ice sheet in a high $\mathrm{CO}_{2}$ climate. J Clim 18:3409-3427

Rignot E, Kanagaratnam P (2006) Changes in the velocity structure of the Greenland ice sheet. Science 311(5763):986-990

Rignot E, Jacobs SS (2002) Rapid bottom melting widespread near Antarctic ice sheet grounding lines. Science 296(5575):2020. doi:10.1126/science. 1070942

Roeckner E, Arpe K, Bengtsson L, Brinkop S, Duemenil L, Esch M, Kirk E, Lunkheit F, Ponater M, Rockel B, Sausen R, Schlese U, Schubert S, Windelband M (1992) Simulation of the present-day climate with the ECHAM model: impact of the model physics and resolution. Max-Planck-Institut für Meteorologie, Hamburg, Report no. 93

Savviin AA, Greve R, Calov R, Muegge B, Hutte K (2000) Simulation of the Antarctic ice sheet with a three-dimensional polythermal ice-sheet model, in support of the EPICA project. II. Nested high-resolution treatment of Dronning Maud Land, Antarctica. Ann Glaciol 30:69-75 
Scambos TA, Bohlander JA, Shuman CA, Skvarca P (2004) Glacier acceleration and thinning after ice shelf collapse in the Larsen B embayment, Antarctica. Geophys Res Lett 31:L18402. doi: 10.1029/2004GL020670

Schaeffer M, Selten FM, Opsteegh JD, Goosse H (2004) The influence of ocean convection patterns on high-latitude climate projections. J Clim 17:4316-4329

Schiller A, Mikolajewicz U, Voss R (1997) The stability of the North Atlantic thermohaline circulation in a coupled ocean-atmosphere general circulation model. Clim Dyn 13:325-347

Schurgers G, Mikolajewicz U, Gröger M, Maier-Reimer E, Vizcaíno M, Winguth A (2007) The effect of land surface changes on Eemian climate. Clim Dyn 29(4):357-373. doi: 10.1007/s00382-007-0237-x

Schurgers G, Mikolajewicz U, Gröger M, Maier-Reimer E, Vizcaíno M, Winguth A (2006) Dynamics of the terrestrial biosphere, climate and atmospheric $\mathrm{CO}_{2}$ concentration during interglacials: a comparison between Eemian and Holocene. Clim Past 2:205-220

Schurgers G, Mikolajewicz U, Gröger M, Maier-Reimer E, Vizcaíno M, Winguth A (2008) Long-term effects of biogeophysical and biogeochemical interactions between terrestrial biosphere and climate under anthropogenic climate change. Accepted for publication in a special issue of Global and Planetary Change

Sclatter JG, Jaupart C, Galson D (1980) The heat flow through oceanic and continental crust and the heat loss of the earth. Rev Geophys Space Phys 18(1):269-311

Shepherd A, Wingham DJ, Mansley JAD (2002) Inland thinning of the Amundsen Sea sector, West Antarctica. Geophys Res Lett 29(10):1364. doi:10.1029/2001GL014183

Sitch S, Smith B, Prentice I, Arneth A, Bondeau A, Cramer W, Kaplan J, Levis S, Lucht W, Sykes M, Thonicke K, Venevsky S (2003) Evaluation of ecosystem dynamics, plant geography and terrestrial carbon cycling in the LPJ dynamic global vegetation model. Global Change Biol 9:161-185

Stommel HH (1961) Thermohaline convection with two stable regimes of flow. Tellus 13:224-230

Stouffer RJ, Yin J, Gregory JM, Dixon KW, Spelman MJ, Hurlin W, Weaver AJ, Eby M, Flato GM, Hasumi H, Hu A, Jungclaus JH, Kamenkovich IV, Levermann A, Montoya M, Murakami S, Nawrath S, Oka A, Peltier WR, Robitaille DY, Sokolov A, Vettoretti G, Weber SL (2006) Investigating the causes of the response of the thermohaline circulation to past and future climate changes. J Clim 19:1365-1387

Sutton RT, Dong B, Gregory JM (2007) Land/sea warming ratio in response to climate change: IPCC AR4 model results and comparison with observations. Geophys. Res Lett 34:L02701. doi:10.1029/2006GL028164

Sweby PK (1984) High-resolution schemes using flux limiters for hyperbolic conservation-laws. SIAM J Num Anal 21:1995-1011
Swingedouw D, Bracconot P, Marti O (2006) Sensitivity of the Atlantic meridional overturning circulation to the melting from northern glaciers in climate change experiments. Geophys Res Lett 33:L07711. doi:10.1029/2006GL025765

Swingedouw D, Bracconot P, Delecluse P, Guilyardi E, Marti O (2007) Quantifying the AMOC feedbacks during a $2 \times \mathrm{CO}_{2}$ stabilization experiment with land-ice melting. Clim Dyn 29:521-534. doi:10.10007/s00382-007-0250-0

Uppala SM, Kallberg PW, Simmons AJ, Andrae U, da Costa Bechtold V, Fiorino M, Gibson J, Haseler J, Hernandez A, Kelly G, Li X, Onogi K, Saarinen S, Sokka N, Allan R, Andersson E, Arpe K, Balmaseda M, Beljaars A, van de Berg L, Bidlot J, Bormann N, Caires S, Chevallier F, Dethof A, Dragosavac M, Fisher M, Fuentes M, Hagemann S, Holm E, Hoskins B, Isaksen L, Janssen P, Jenne R, McNally A, Mahfouf JF, Morcrette JJ, Rayner N, Saunders R, Simon P, Sterl A, Trenberth K, Untch A, Vasiljevic D, Viterbo P, Woollen J (2005) The ERA-40 re-analysis. Q J R Meteor Soc 131:2961-3012

Toniazzo T, Gregory JM, Huybrechts P (2004) Climatic impact of a Greenland deglaciation and its possible irreversibility. J Clim $17: 21-33$

Vizcaíno M (2006) Long-term interactions between ice sheets and climate under anthropogenic greenhouse forcing. Simulations with two complex earth system models. Berichte zur Erdsystemforschung 30. http://www.mpimet.mpg.de/fileadmin/ publikationen/Reports/BzE_30.pdf

Voss R, Sausen R (1996) Techniques for asynchronous and periodically synchronous coupling of atmosphere and ocean models. Part II: impact of variability. Clim Dyn 12:605-614

Voss R, Mikolajewicz U (2001) Long-term climate changes due to increased $\mathrm{CO}_{2}$ concentration in the coupled atmosphere-ocean general circulation model ECHAM3/LSG. Clim Dyn 17:45-60

Wang Z, Mysak L (2002) Simulation of the last glacial inception and rapid ice sheet growth in the McGill Paleoclimate model. Geophys Res Lett 29(23):2102. doi:10.1029/2002GL015120

Warner R, Budd W (1998) Modelling the long term response of the Antarctic ice sheet to global warming. Ann Glaciol 27:161

Wild M, Calanca P, Scherrer S, Ohmura A (2003) Effects of polar ice sheets on global sea level in high resolution greenhouse scenarios. J Geophys Res 108:4165

Wild M, Ohmura A (2000) Changes in the mass balance of the polar ice sheets and sea level from high resolution GCM simulations of global warming. Ann Glaciol 30:197-203

Winguth A, Mikolajewicz U, Gröger M, Maier-Reimer E, Schurgers G, Vizcaíno M (2005) Centennial-scale interactions between the carbon cycle and anthropogenic climate change using a dynamic Earth system model. Geophys Res Lett 32(23):L23714. doi: 10.1029/2005GL023681 